Article

\title{
Analysis of Volatile Organic Compounds during the OCTAVE Campaign: Sources and Distributions of Formaldehyde on Reunion Island
}

\author{
Manon Rocco ${ }^{1, *}$, Aurélie Colomb ${ }^{1}$, Jean-Luc Baray ${ }^{1}$ (D) Crist Amelynck ${ }^{2,3}$, Bert Verreyken ${ }^{2,3,4}$, \\ Agnès Borbon ${ }^{1}$, Jean-Marc Pichon ${ }^{1}$, Laetitia Bouvier ${ }^{1}$, Niels Schoon ${ }^{2}$, Valérie Gros ${ }^{5}$, \\ Roland Sarda-Esteve ${ }^{5}$, Pierre Tulet ${ }^{4}{ }^{(}$, Jean-Marc Metzger ${ }^{6}$, Valentin Duflot ${ }^{4}$, \\ Christian Guadagno ${ }^{7}$, Guillaume Peris ${ }^{7}$ and Jérôme Brioude ${ }^{4}$ \\ 1 Laboratoire de Météorologie Physique, UMR 6016, CNRS, Université Clermont Auvergne, 63178 Aubière, \\ France; A.Colomb@opgc.univ-bpclermont.fr (A.C.); J.L.Baray@opgc.fr (J.-L.B.); \\ A.Borbon@opgc.univ-bpclermont.fr (A.B.); J.M.Pichon@opgc.fr (J.-M.P.); 1.bouvier@opgc.fr (L.B.) \\ 2 Royal Belgian Institute for Space Aeronomy (BIRA-IASB), B-1180 Brussels, Belgium; \\ crist.amelynck@aeronomie.be (C.A.); bert.verreyken@aeronomie.be (B.V.); niels.schoon@aeronomie.be (N.S.) \\ 3 Department of chemistry, Ghent University, B-9000 Ghent, Belgium \\ 4 Laboratoire de l'Atmosphère et des Cyclones, UMR8105, CNRS, Météo-France, Université de la Réunion, \\ 97715 Saint-Denis, France; pierre.tulet@univ-reunion.fr (P.T.); valentin.duflot@univ-reunion.fr (V.D.); \\ jerome.brioude@univ-reunion.fr (J.B.) \\ 5 Laboratoire des Sciences du Climat et de l’Environnement, UMR 8212, CEA, CNRS, Université Versailles \\ Saint Quentin, 91198 Gif-sur-Yvette, France; valerie.gros@lsce.ipsl.fr (V.G.); \\ roland.sarda-esteve@lsce.ipsl.fr (R.S.-E.) \\ 6 Observatoire des Sciences de l'Univers de La Réunion, UMS3365, 97744 Saint-Denis, France; \\ jean-marc.metzger@univ-reunion.fr \\ 7 ATMO-Réunion, 97438 Sainte-Marie, France; christian.guadagno@atmo-reunion.net (C.G.); \\ guillaume.peris@atmo-reunion.net (G.P.) \\ * Correspondence: manon.rocco@uca.fr; Tel.: +33-473-407-373
}

Received: 28 November 2019; Accepted: 22 January 2020; Published: 27 January 2020

check for updates

\begin{abstract}
The Oxygenated Compounds in the Tropical Atmosphere: Variability and Exchanges (OCTAVE) campaign aimed to improve the assessment of the budget and role of oxygenated volatile organic compounds (OVOCs) in tropical regions, and especially over oceans, relying on an integrated approach combining in situ measurements, satellite retrievals, and modeling. As part of OCTAVE, volatile organic compounds (VOCs) were measured using a comprehensive suite of instruments on Reunion Island $\left(21.07^{\circ} \mathrm{S}, 55.38^{\circ} \mathrm{E}\right)$ from 7 March to 2 May 2018. VOCs were measured at a receptor site at the Maïdo observatory during the entire campaign and at two source sites: Le Port from 19 to 24 April 2018 (source of anthropogenic emissions) and Bélouve from 25 April to 2 May 2018 (source of biogenic emissions) within a mobile lab. The Maïdo observatory is a remote background site located at an altitude of $2200 \mathrm{~m}$, whereas Bélouve is located in a tropical forest to the east of Maïdo and Le Port is an urban area located northwest of Maïdo. The major objective of this study was to understand the sources and distributions of atmospheric formaldehyde (HCHO) in the Maïdo observatory on Reunion Island. To address this objective, two different approaches were used to quantify and determine the main drivers of $\mathrm{HCHO}$ at Maïdo. First, a chemical-kinetics-based (CKB) calculation method was used to determine the sources and sinks (biogenic, anthropogenic/primary, or secondary) of $\mathrm{HCHO}$ at the Maïdo site. The CKB method shows that $9 \%$ of the formaldehyde formed from biogenic emissions and $89 \%$ of $\mathrm{HCHO}$ had an unknown source; that is, the sources cannot be explicitly described by this method. Next, a positive matrix factorization (PMF) model was applied to characterize the VOC source contributions at Maïdo. The PMF analysis including VOCs measured at the Maïdo observatory shows that the most robust solution was obtained with five factors: secondary biogenic accounting for $17 \%$, primary anthropogenic/solvents $(24 \%)$, primary biogenic $(14 \%)$, primary
\end{abstract}


anthropogenic/combustion (22\%), and background (23\%). The main contributions to formaldehyde sources as described by the PMF model are secondary biogenic (oxidation of biogenic VOCs with $37 \%)$ and background (32\%). Some assumptions were necessary concerning the high percentage of unknown $\mathrm{HCHO}$ sources of the $\mathrm{CKB}$ calculation method such as the biogenic emission factor resulting in large discrepancies between the two methods.

Keywords: volatile organic compounds (VOCs); formaldehyde sources; positive matrix factorization (PMF); kinetic chemical equations

\section{Introduction}

Volatile organic compounds (VOCs) are key components of the atmosphere: they are precursors of secondary organic aerosol (SOA) and lead to the photochemical formation of air pollutants such as tropospheric ozone [1-5]. These compounds can be emitted by anthropogenic (mobile sources, industry, solvents) and biogenic (tree leaves, plant growth) sources. Several studies quantified the respective roles of biogenic [6,7] and anthropogenic [8-12] emissions of VOCs. Biogenic emissions are directly dependent on meteorological conditions, such as high temperatures and solar radiation, which increase VOC production and emission by vegetation [13].

Oxygenated Compounds in the Tropical Atmosphere: Variability and Exchanges (OCTAVE) is an international French-Belgian program with the aim of improving assessment of the budget and role of oxygenated volatile organic compounds (OVOCs) in tropical regions, and especially over oceans, relying on an integrated approach combining in situ measurements, satellite retrievals, and modeling. One of the specific objectives of the project is to study and describe the repartitioning and sources of VOCs and particularly OVOCs at the Maïdo site on Reunion Island in the Indian Ocean. An intensive field campaign was conducted from 7 March to 2 May 2018 to improve our understanding of the sources and sinks of OVOCs in this environment. In this context, measurements of formaldehyde and other VOCs (OVOCs such as acetaldehyde, acetone, methanol; non-methane hydrocarbons (NMCHs) such as benzene, toluene, ethylbenzene, xylenes (BTEX), isoprene, and monoterpenes; and volatile organic sulfur such as dimethyl sulfide/DMS) were recorded. Formaldehyde is a carcinogenic substance [14] and a long exposure to and inhalation of formaldehyde cause skin and respiratory tract irritations [15]. It plays a major role in the oxidative capacity of the atmosphere with a strong production of hydroxyl radicals [16]. This compound can result from primary or secondary formation by anthropogenic (combustion, solvents) or biogenic sources, of which one-third results from primary emissions and two-thirds from secondary formation [17]. The secondary formation of $\mathrm{HCHO}$ results principally from VOCs (as isoprene, methacrolein (MACR) or methyl vinyl ketone (MVK)) oxidation by atmospheric oxidants such as the $\mathrm{OH}$ radical. The most prominent reaction is isoprene oxidation due to its importance in the atmosphere. Isoprene is the most emitted biogenic non-methane VOC on the global scale [18], being the main precursor of $\mathrm{HCHO}$ in the lower troposphere [18-20]

Our goal in this study was to better estimate sources and sinks of VOCs compounds, especially HCHO. We combined a chemical-kinetics-based approach with a multivariate statistical approach to determine the sources and sinks of $\mathrm{HCHO}$ at the Maïdo observatory on Reunion Island $\left(21.1^{\circ} \mathrm{S}\right.$, $55.4^{\circ} \mathrm{E}, 2200 \mathrm{~m}$ above sea level (a.s.l.)) [21]. In the chemical-kinetics-based approach, HCHO sources and sinks were calculated, solving the chemical kinetics equations according to different hypotheses. The second approach involved a positive matrix factorization (PMF). PMF is a tool developed by the U.S. Environmental Protection Agency [22], allowing the characterization of VOC sources and quantifying their contribution to samples. Multiple studies have applied the PMF technique to study primary or secondary sources of VOCs [23], the difference between rural (biogenic) and urban (anthropogenic) sites [24-26], or chemical and dynamical influence on the sources [27]. 
The remainder of this paper is structured as follows: Section 2 describes the materials and methods, including meteorological conditions and sampling sites (Section 2.1), instrumentation (Section 2.2), methodology of the chemical kinetic-based calculation method (Section 2.3), and PMF approach (Section 2.4). The results are presented and discussed in Section 3 with regards to dynamic context obtained by determining the origins of different air masses with meteorological measurements during the campaign. In Section 3.1, measurements of VOCs at the Maïdo observatory and Bélouve are presented. Then, the results of the chemical-kinetics-based and PMF approaches are discussed in Sections 3.2 and 3.3 respectively.

\section{Material and Methods}

\subsection{Meteorological Conditions and Sampling Sites}

The main reactive gases, including VOC, nitrogen oxides $\left(\mathrm{NO}_{\mathrm{x}}=\mathrm{NO}+\mathrm{NO}_{2}\right)$, ozone $\left(\mathrm{O}_{3}\right)$, and sulfur dioxide $\left(\mathrm{SO}_{2}\right)$, were measured at the Maïdo observatory on Reunion Island. The observatory is located above a tamarind tree forest and close to scrubland. Measurements were recorded in an urban site at Le Port $\left(20.9^{\circ} \mathrm{S}, 55.3^{\circ} \mathrm{E}, 7 \mathrm{~m}\right.$ a.s.l.) and at the Bélouve lodges (called hereafter Bélouve, $21.06^{\circ} \mathrm{S}, 55.5^{\circ} \mathrm{E}, 1498 \mathrm{~m}$ a.s.l.) to study the influence of anthropogenic and biogenic VOC emissions. Le Port is an industrial (e.g., sugar factory) area located in the northwest of the island along the coast. In contrast, Bélouve is located in a primary tropical forest located $16 \mathrm{~km}$ east of the Maïdo observatory. Figure 1 presents the location of each measurement site and the main features of local low-level winds. The climate is tropical with wet and hot summers with a cyclonic season from November to March and, depending on the altitude, mild to cool winters from May to September. $\mathrm{VOCs}, \mathrm{NO}_{\mathrm{x}}, \mathrm{O}_{3}$, and $\mathrm{SO}_{2}$ concentrations were measured at the end of the cyclonic season, and the temperatures observed during the campaign varied between 12 and $16^{\circ} \mathrm{C}$ at the Maïdo observatory, 23 and $29{ }^{\circ} \mathrm{C}$ at Le Port, and 4 to $12{ }^{\circ} \mathrm{C}$ at Bélouve. Three cyclones occurred during the campaign: Dumazile from 1 March to 6 March, Eliakim from 13 March to 20 March, and Fakir from 20 April to 24 April. Volcanic eruptions occurred 3 April during few hours and from 27 April to 1 June.

On the synoptic scale, under the influence of trade winds, air masses are mainly advected toward the northwest over the mountains of Reunion Island, known as the over-flow phenomenon [28-30]. The observatory is also influenced by local air circulation patterns with thermodynamic processes linked to upslope and downslope winds such as the catabatic-anabatic slope winds and sea-land breeze. The Maïdo observatory is located in the convergence of these two distinct regimes, and during the daytime, the trade winds are broken into two flows forming a return flow in the northwest of the island. Then, the surface is heated by solar radiation, resulting in upward air masses advecting to the Maïdo observatory. These air masses are mostly within the marine boundary layer (MBL), which contains biogenically- or anthropogenically-emitted compounds [28]. In contrast, during the night, the observatory is mostly in the free troposphere, the surface cools, and air masses move downward [28-31].

Figure 2 presents the spatial distribution of back-trajectories points during the measurement campaign period. They were calculated with LACYTRAJ [32], a three-dimensional Lagrangian code based on ECMWF $1 \times 1$ degree ERA interim reanalysis winds. Although ERA interim data spatial resolution at mesoscale circulation for the complex Reunion Island terrain is not resolved by LACYTRAJ, the trajectories can be used to identify the origins of air masses from the atmospheric transport at the synoptic scale. The wind direction is divided in 8 sections. We calculated $36 \mathrm{~h}$ back-trajectories every $6 \mathrm{~h}$ throughout the month of April starting from the Maïdo observatory (2200 m a.s.l.). Each wind proportion value was calculated considering the number of trajectory points in the corresponding section relative to the total amount of trajectory points. Figure 2 presents the dominant air masses origins during April 2018. The results confirm that the dominant large-scale air masses are easterly $(\mathrm{NEE}=24.4 \%$ and $\mathrm{SEE}=32.9 \%)$ under the influence of trade winds. 


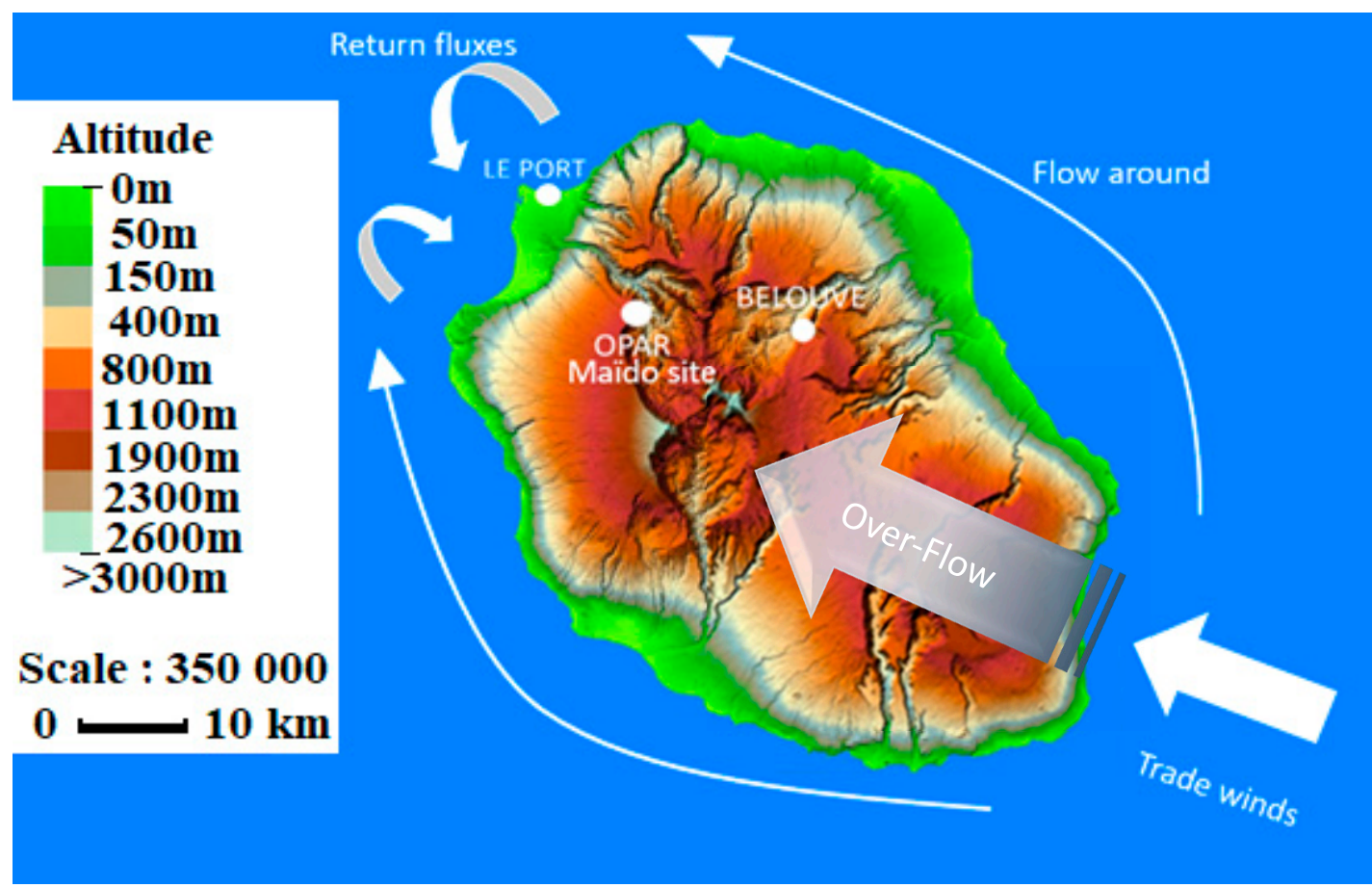

Figure 1. Situation map showing the location of the different measurement sites: Le Port, Bélouve, and Maïdo and wind patterns: flow around, over-flow and return flow.

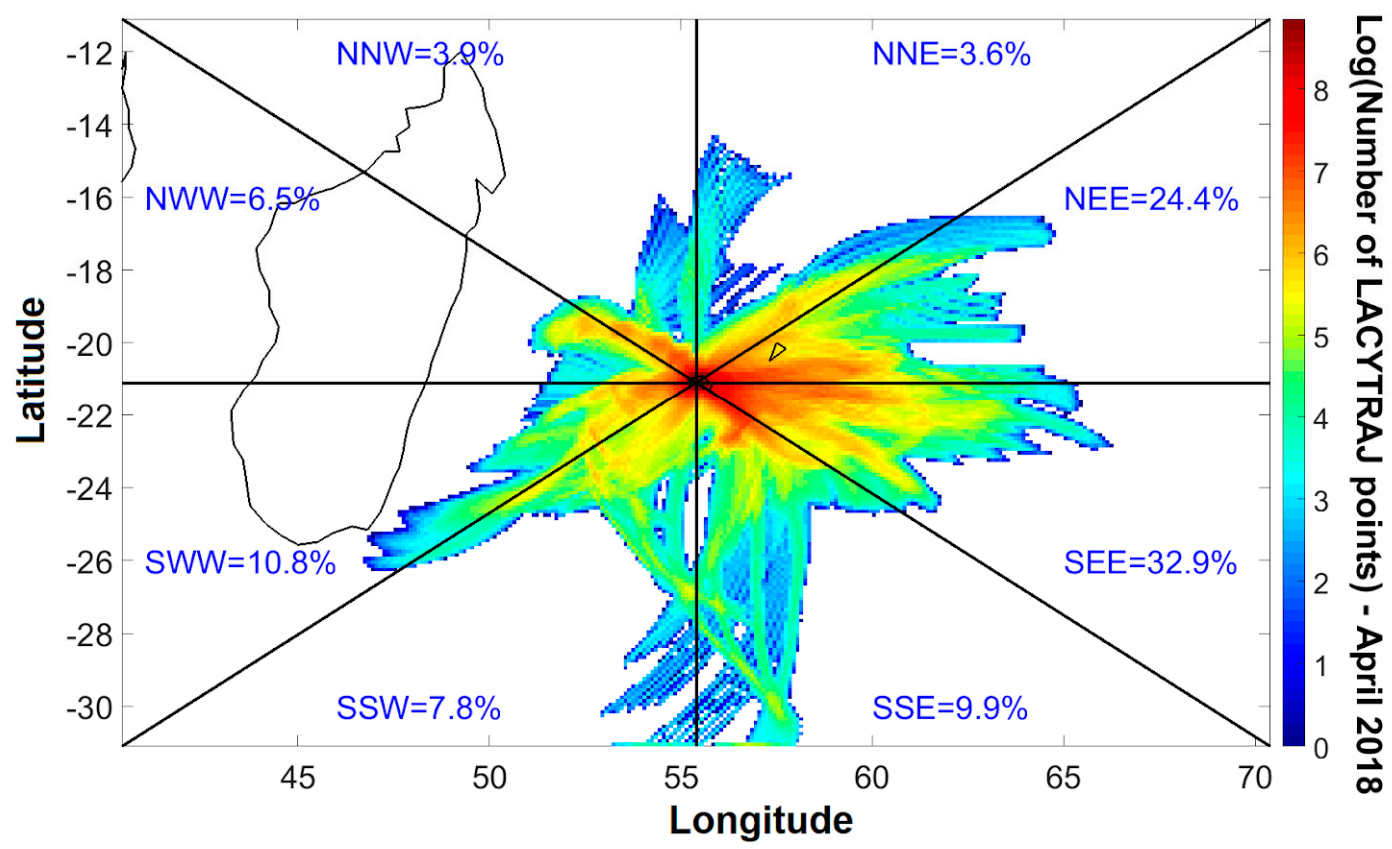

Figure 2. Number of back-trajectories points (color bar) and percentage per direction sectors (in blue) in April 2018.

\subsection{Instrumentation}

OVOCs were measured using online proton transfer reaction-mass spectrometry (PTR-MS). Formaldehyde $(\mathrm{HCHO})$ was measured via chemical fluorometric detection with an Aerolaser instrument (AL 4021 model; Garmisch-Partenkirchen, Germany) (Section 2.2.2). Estimation of uncertainties of the different instruments is provided in the supplementary section and the characteristics of the instruments are summarized in Table 1. 
Table 1. Online instrumentation during Oxygenated Compounds in the Tropical Atmosphere: Variability and Exchanges (OCTAVE) campaign. BIRA: Royal Belgian Institute for Space Aeronomy, LSCE: Laboratoire des sciences du Climat et de l'Environnement, LACY: Laboratoire de l'Atmosphère et des CYclones, LaMP: Laboratoire de Météorologie Physique, ATMO: Atmo-Réunion.

\begin{tabular}{|c|c|c|c|c|c|c|}
\hline Measurements & Site & $\begin{array}{l}\text { Recorded Dates } \\
\text { (DD/MM/YY) }\end{array}$ & Institution & Instrument & $\begin{array}{c}\text { Limit of } \\
\text { Detection }(p p b)\end{array}$ & Absolute Uncertainty \\
\hline \multirow{2}{*}{ VOCs } & \multirow{2}{*}{ Maïdo } & $16 / 03 / 18-25 / 05 / 18$ & BIRA & PTR-quad-MS & $0.011-0.145$ & $0.004-0.84 \mathrm{ppb}$ \\
\hline & & 06/04/18-16/04/18 & LSCE & PTR-quad-MS & $0.018-0.532$ & $0.006-0.09 \mathrm{ppb}$ \\
\hline & Bélouve & 25/04/18-02/05/18 & LSCE & PTR-quad-MS & $0.018-0.532$ & $0.009-0.08 \mathrm{ppb}$ \\
\hline & Le Port & 20/04/18 (1 day) & LSCE & PTR-quad-MS & $0.018-0.532$ & $0.006-0.34 \mathrm{ppb}$ \\
\hline \multirow{3}{*}{$\mathrm{NO}_{x}$} & Maïdo & 08/03/18-10/05/18 & LACY & API Teledyne & $5 \times 10^{-2}$ & $0.5 \%$ \\
\hline & Bélouve & $25 / 04 / 18-02 / 05 / 18$ & ATMO & T200 UP & 0.4 & $0.5 \%$ \\
\hline & Le Port & $16 / 04 / 18-24 / 04 / 18$ & ATMO & $\begin{array}{l}\text { Teledyne T200 } \\
\text { Teledyne T200 }\end{array}$ & 0.4 & $0.5 \%$ \\
\hline \multirow{3}{*}{$\mathrm{O}_{3}$} & Maïdo & 08/03/18-10/05/18 & LACY & TEI 49i & 0.5 & $1 \mathrm{ppb}$ \\
\hline & Bélouve & 25/04/18-02/05/18 & ATMO & Teledyne T400 & 0.6 & $0.5 \%$ \\
\hline & Le Port & $16 / 04 / 18-24 / 04 / 18$ & ATMO & Teledyne T400 & 0.6 & $0.5 \%$ \\
\hline \multirow{3}{*}{ HCHO (Aerolaser) } & Maïdo & $12 / 03 / 18-19 / 04 / 18$ & LaMP & Aerolaser & 0.15 & $10.3 \%$ \\
\hline & Bélouve & $26 / 04 / 18-02 / 05 / 18$ & LaMP & Aerolaser & 0.15 & $10.3 \%$ \\
\hline & Le Port & 23/04/18-24/04/18 & LaMP & Aerolaser & 0.15 & $10.3 \%$ \\
\hline \multirow{3}{*}{$\begin{array}{c}\text { Meteorological parameters } \\
\text { (temperature }(\mathrm{T}), \text { relative humidity } \\
(\mathrm{RH}) \text {, pressure }(\mathrm{P}), \text { wind speed (WS), } \\
\text { wind direction }(\mathrm{WD}))\end{array}$} & Maïdo & $01 / 03 / 18-02 / 05 / 18$ & BIRA & \multirow{3}{*}{$\begin{array}{l}\text { HUMICAP 180, Pt100 } \\
\text { temperature, Vaisala } \\
\text { PTB100 }\end{array}$} & NA & \multirow{3}{*}{$\begin{array}{c}\left(\mathrm{RH} \pm 2 \%, \mathrm{~T} \pm 0.2{ }^{\circ} \mathrm{C}\right. \\
\mathrm{P} \pm 0.5 \mathrm{hPa}, \mathrm{WS} \pm 0.17 \mathrm{~m} / \mathrm{s} \\
\left.\mathrm{WD} \pm 2.8^{\circ}\right)\end{array}$} \\
\hline & Bélouve & $25 / 04 / 18-02 / 05 / 18$ & ATMO & & NA & \\
\hline & Le Port & $16 / 04 / 18-24 / 04 / 18$ & ATMO & & NA & \\
\hline
\end{tabular}




\subsubsection{PTR-MS}

PTR-MS is a widely used online technique for VOC detection with a high sensitivity (10-100 pptv detection limit) and a fast response time $\left(\sim 100 \times 10^{-3} \mathrm{~s}\right)$ [33]. It relies upon chemical ionization of VOCs in ambient air by proton transfer from reactant $\mathrm{H}_{3} \mathrm{O}^{+}$source ions, which are produced in large amounts in a hollow cathode discharge ion source and subsequently injected in an ambient air flow which is pumped through a drift tube reactor. The reaction is $\mathrm{H}_{3} \mathrm{O}^{+}+\mathrm{R} \rightarrow \mathrm{RH}^{+}+\mathrm{H}_{2} \mathrm{O}$.

Reactant and product ions are sampled downstream of the reactor and detected by a quadrupole mass spectrometer. VOC identification relies on $\mathrm{m} / \mathrm{z}$ ratios of the protonated VOCs, and quantification relies either upon calibration of the compound specific product ion signals using a VOC standard or upon $\mathrm{H}_{3} \mathrm{O}^{+} / \mathrm{VOC}$ reaction kinetics and ion residence time in the reactor. More details can be found in Blake et al. [34].

VOCs were measured by two proton-transfer-reaction quadrupole mass spectrometers (PTR-Quad-MS; Ionicon Analytik GmbH, Innsbruck, Austria) belonging to the Royal Belgian Institute for Space Aeronomy (BIRA-IASB) and to the Laboratoire des Sciences du Climat et de l'Environnement (LSCE). The BIRA PTR-MS was installed at the Maïdo observatory in 2017 to generate a 2-year dataset of atmospheric measurements of OVOCs. The LSCE PTR-MS measurements were recorded during the campaign at the three different locations. First, BIRA and LSCE PTR-MS were compared at the Maido observatory (during 6-16 April 2018) to validate the measurements. The coefficient of determination $\left(R^{2}\right)$ was higher than 0.90 with $\mathrm{y}=0.91 \mathrm{x}+0.43$ during the calibration with Ionicon and Apel-Riemer mixture (ApelRiemer Environmental Inc., USA) with $m / z$ 33, 42, 45, 59, 69, 73, 79, 93, and 107; with $\mathrm{x}=$ BIRA calibration coefficients and $\mathrm{y}=$ LSCE calibration coefficients. Afterward, the LSCE PTR-MS was moved to Le Port (19-24 April 2018) and Bélouve (25 April-2 May 2018) in a mobile laboratory.

In the autumn of 2017 (about 6 months before the OCTAVE campaign), the LSCE PTR-MS was deployed in the first international PTR-MS intercomparison campaign at Cabauw, the Netherlands. This instrument showed good comparison with the other deployed PTR-MS (mostly Proton Transfer "Time-of-Flight" Mass Spectrometer, PTR-TOF-MS, Ionicon, Innsbruck, Austria), its sensitivity was in the range of the other instruments until $\mathrm{m} / \mathrm{z} 150$ and a low variability to humidity. More details about the results of this intercomparison are provided by Holzinger et al. [35].

The VOC mixing ratios presented in this work used for PMF analysis were recorded at the Maïdo site with the BIRA PTR-MS. Many VOCs were sampled continuously for both instruments: methanol $(m / z 33)$, acetonitrile $(m / z 42)$, acetaldehyde $(m / z 45)$, acetone $(m / z 59)$, dimethyl sulfide (DMS) $(m / z$ 63), isoprene $(m / z 69)$, methyl vinyl ketone (MVK) + methacrolein (MACR) + isoprene hydroxy hydro peroxides (ISOPOOHs) $(\mathrm{m} / \mathrm{z} 71)$, methyl ethyl ketone ()$(\mathrm{m} / \mathrm{z} 73)$, benzene $(\mathrm{m} / \mathrm{z} 79)$, toluene $(\mathrm{m} / \mathrm{z}$ 93), xylenes $(m / z 107)$, and monoterpenes $(m / z 137$ and 81$)$ [36,37] with a dwell time of $10 \mathrm{~s}$ per mass. BIRA PTR-MS background measurements were recorded every $4 \mathrm{~h}$ and lasted for about $25 \mathrm{~min}$ by sampling zero air, which was generated by a Parker HPZA-3500 catalytic converter (Parker Hannifin Corporation, Haverhill, USA). We measured the blanks after sending $1 \mathrm{~L}$ of air through the catalytic converter and this air was subsampled from the main sampling line. Negative values indicate that a compound must have been generated in the catalytic converter or in the tubing of the zero-air set-up that gives rise to ion species in the PTR-MS (e.g., $m / z 93$ and 107). Negative concentrations occur when free tropospheric air masses are sampled. Concentrations below zero were not considered in the calculation. The instrument for the VOCs of interest was calibrated by dynamically diluting a small flow of a calibration gas standard (Apel-Riemer Environmental, Inc., Boulder, CO, USA) in zero air. Calibrations were conducted every 3 days and the dependence of the calibration coefficients on sample humidity was determined about every two months.

Concerning the LSCE PTR-MS, the ambient air at Le Port and Bélouve was sampled through a heated and thermally insulated Teflon line, and a particle filter was set in front of the inlet to avoid aerosols and other particles above $2 \mu \mathrm{m}$ to enter the instrument. One-hour blank measurements were recorded with an $8 \mathrm{~h}$ repetition rate. Then, for concentration calculations, these measures were 
subtracted from the atmospheric signal. A calibration was performed at the beginning, in the middle, and at the end of the campaign using a gas calibration unit (GCU) from Ionicon Analytik (Innsbruck, Austria)that contained a known and calibrated VOC mixture. As the calibrations produced similar results (within 94\%), a mean calibration coefficient was applied to the whole campaign.

Both instruments were operated at a drift tube pressure and temperature of $2.2 \mathrm{mbar}$ and $333 \mathrm{~K}$, respectively, and a drift voltage of $600 \mathrm{~V}$. This voltage results in an $\mathrm{E} / \mathrm{N}$ ratio of 130 Townsend $\left(1 \mathrm{Td}=10^{-17} \mathrm{~V} \mathrm{~cm}^{2}\right)$, where $\mathrm{E}$ is the electrical field strength and $\mathrm{N}$ is the buffer gas number density.

\subsubsection{Additional Measurements}

The Aerolaser GmbH (AL 4021 model; Garmisch-Partenkirchen, Germany) instrument determines $\mathrm{HCHO}$ concentrations based on the Hantzsch reaction [38] and fluorescence detection [39]. Two solutions were prepared: a stripping solution and a Hantzsch (or reagent) solution. The stripping solution was composed of $3 \mathrm{~mL}$ sulfuric acid $\left(\mathrm{H}_{2} \mathrm{SO}_{4}\right)$ in $1 \mathrm{~L}$ of water. Air was sampled through a $6 \mathrm{~mm}$ internal diameter Teflon tube and gaseous $\mathrm{HCHO}$ was transferred into the stripping liquid solution. We prepared $1 \mathrm{~L}$ of reagent solution with $77 \mathrm{~g}$ of ammonium acetate, $2.5 \mathrm{~mL}$ of acetic acid at $100 \%$, and $2 \mathrm{~mL}$ of acetylacetate. This solution converted the formaldehyde into 3,5-diacetyl-1,4-dihydrolutidine (DDL). This molecule fluoresces at $510 \mathrm{~nm}$ after excitation at $400 \mathrm{~nm}$ and the fluorescence intensity was detected by a photomultiplier. A calibration was performed at the beginning of the campaign within a $30 \mu \mathrm{g} / \mathrm{L} \mathrm{HCHO}$ solution. Blank measurements were performed every 2 days with distilled water.

The instrument recorded measurements at Maïdo from 12 to 19 March 2018. Afterward, it was moved to Le Port from 20 to 24 April 2018 and to Bélouve from 25 April to 2 May 2018 within the mobile laboratory.

Other trace gases and meteorological parameters were also measured at different sites. $\mathrm{O}_{3}$ was measured at the Maïdo observatory and Bélouve and Le Port using a UV photometric analyzer (TEI49i, Thermo Fisher Scientific, Waltham, MA USA or Teledyne T400, Teledyne API, San Diego, CA, USA).

$\mathrm{NO}$ and $\mathrm{NO}_{2}$ were measured along with ozone chemiluminescence analyzer using blue light converter (BLC) technology to convert $\mathrm{NO}_{2}$ into $\mathrm{NO}$ at a specific wavelength [40].

Wind speed and direction were measured using a Vaisala HMP45 sensor (Vaisala, Helsinki, Finland). The meteorological parameters (temperature, relative humidity, pressure, and wind speed and direction) were recorded by an automatic weather system.

Each instrument is specified in Table 1.

\subsection{CKB Calculation to Estimate Primary and Secondary Sources of Formaldehyde at Maido Receptor Site}

In several studies, chemical kinetics equations have been solved to deduce the photochemical age of air masses; Yuan et al. [23] and Parrish et al. [41] used this method to determine concentrations of nonmethane hydrocarbons (NMHCs) and VOCs. Fried et al. also estimated HCHO sources by solving photochemical equations [42].

In the present study, we used chemical kinetics equations to determine the sources of formaldehyde and to recalculate concentrations considering biogenic and anthropogenic components of emissions. Formaldehyde concentrations at the Maïdo observatory were assumed to result from both primary and secondary anthropogenic and biogenic emissions, and were described by the following expression:

$$
\begin{gathered}
{[\mathrm{HCHO}]_{\text {measured }}=[\mathrm{HCHO}]_{\text {primary anthropogenic }}+[\mathrm{HCHO}]_{\text {primary biogenic }}+} \\
{[\mathrm{HCHO}]_{\text {secondary biogenic }}+[\mathrm{HCHO}]_{\text {secondary anthropogenic }}}
\end{gathered}
$$

Primary terms were deduced from anthropogenic and biogenic direct emissions ([HCHO] primary anthropogenic and $[\mathrm{HCHO}]_{\text {primary biogenic, }}$ respectively). Secondary terms ([HCHO $]_{\text {secondary anthropogenic }}$ and $[\mathrm{HCHO}]_{\text {secondary biogenic }}$ ) consider the concentrations of key species (e.g., isoprene, toluene, and monoterpenes) and the corresponding yield formation rates. 
This section is organized into 3 steps. First, the calculation of primary and anthropogenic and biogenic sources of HCHO is described. The VOC concentrations used for the calculations were from the BIRA PTR-MS data, except for formaldehyde for which Aerolaser (AL 4021 model; Garmisch-Partenkirchen, Germany) data were used. The second step details the secondary and anthropogenic and biogenic sources of HCHO. The equations used for these two calculations included the atmospheric transport time $t$, which is determined in the third step. This section presents the main equations of the CKB approach. A more exhaustive version containing all calculations is provided in Appendix B.

\subsubsection{Estimation of the Primary Anthropogenic and Biogenic Contributions to $\mathrm{HCHO}$}

\section{Primary Anthropogenic Contribution}

$[\mathrm{HCHO}]$ primary anthropogenic, the primary anthropogenic contribution to $\mathrm{HCHO}$, was estimated using toluene as an anthropogenic tracer. Toluene is one of the most abundant compounds emitted by traffic. Biogenic sources of toluene exist, with a toluene to $\alpha$-pinene flux ratio of $10^{3}$ for pine trees [43]. By solving the differential equations describing the loss of toluene and $\mathrm{HCHO}$ by reaction with $\mathrm{OH}$ along the air mass trajectory between the urban site at Le Port and the Maïdo observatory,

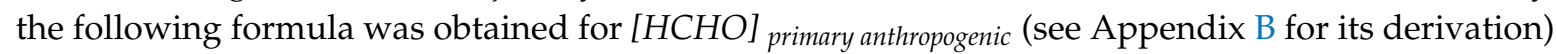
and was mentioned before in Possanzini et al. [44]:

$$
[\mathrm{HCHO}]_{\text {primary anthropogenic }}=\rho \times[\text { toluene }]_{t} \times e^{\left(\left(k_{1}-k_{2}\right)[\mathrm{OH}]-J_{\mathrm{HCHO}}\right) t}
$$

where $[\text { toluene }]_{t}$ is the concentration of toluene, and negative values were not considered for the calculation; $\rho$ is the formaldehyde to toluene concentration ratio at the urban site, $4.5 \pm 0.8$ in this study, and this value is close from the one in Equation (5) measured by Zhang et al. in Beijing [45]; $t$ is the air mass transport time in seconds (cf. Section 2.3.3); $k_{1}=5.96 \times 10^{-12} \mathrm{~cm}^{3}$ molecules ${ }^{-1} \mathrm{~s}^{-1}$ and $k_{2}=9.77 \times 10^{-12} \mathrm{~cm}^{3}$ molecules ${ }^{-1} \mathrm{~s}^{-1}$ are the reaction rate constants of toluene and formaldehyde with the $\mathrm{OH}$ radical, respectively [46]; $J_{\mathrm{HCHO}}$ is the photolysis rate of formaldehyde deduced by the tropospheric and ultraviolet visible radiation (TUV) model published on the National Center for Atmospheric Research (NCAR) website (Appendix B); and $[\mathrm{OH}]$ is the $\mathrm{OH}$ concentration deduced (cf. the Appendix B) by:

$$
[\mathrm{OH}] \times t=\frac{\ln \left(\frac{[\text { toluene }]}{3 \times[\text { benzene }]}\right)}{\left(k_{\text {benzene }}-k_{1}\right)} .
$$

where $k_{1}=5.96 \times 10^{-12} \mathrm{~cm}^{3}$ molecules ${ }^{-1} \mathrm{~s}^{-1}$ and $k_{\text {benzene }}=1.23 \times 10^{-12} \mathrm{~cm}^{3}$ molecules ${ }^{-1} \mathrm{~s}^{-1}$, and $t$ is the calculated transport time.

This method was replicated from Yuan et al. who used the $(m+p)$-xylene to benzene ratio [23]. The two components (benzene and toluene) were chosen for the large difference between $k_{b e n z e n e}$ and $k_{\text {toluene }}$. The photochemical kinetics allows $[\mathrm{OH}] \times t$ to be estimated from the toluene to benzene ratio [47].

\section{Primary Biogenic Contribution}

$[\mathrm{HCHO}]_{\text {primary biogenic, }}$ the primary biogenic contribution to $\mathrm{HCHO}$, was estimated using terpenes as the biogenic tracer [5]. [HCHO] primary biogenic considers the reaction of monoterpenes with the $\mathrm{OH}$ radical and $\mathrm{O}_{3}$ :

$$
[\mathrm{HCHO}]_{\text {primary biogenic }}=\psi \times[\text { terpenes }]_{t} \times e^{\left(\left(k_{\mathrm{OH}}-k_{2}\right)[\mathrm{OH}]+k_{\mathrm{O}}[\mathrm{O} 3]-j_{\mathrm{HCHO}}\right) t}
$$

where $\Psi$ is the ratio of biogenic formaldehyde to monoterpenes concentrations at the forest site. For Eucalypt grandis and Eucalypt camaldulensis, minor species present on Reunion island, the ratio ranges between 0.02 and 0.2 in Australia [48]. This ratio has not been measured during the campaign, 
so a value of 0.129 , from the mean of values of these two species as obtained for Quercus ilex [49] in Mediterranean Basin, was used instead. $[\mathrm{OH}]$ is the concentration of $\mathrm{OH}$ radicals in molecule $\mathrm{cm}^{-3}$ :

$$
[\mathrm{OH}]=\frac{2 \times J_{\mathrm{HCHO}} \times[\mathrm{HCHO}]+2 \times J_{\mathrm{O} 3} \times \frac{k_{\beta}}{k_{\alpha}} \times \frac{\left[\mathrm{O}_{3}\right] \times\left[\mathrm{H}_{2} \mathrm{O}\right]}{M_{\text {air }}}}{k_{\mathrm{NO} 2} \times\left[\mathrm{NO}_{2}\right]}
$$

where $[\mathrm{HCHO}],\left[\mathrm{NO}_{2}\right]$, and $\left[\mathrm{O}_{3}\right]$ are the concentrations of each species in molecule $\mathrm{cm}^{-3} ; k_{\alpha}$ is the rate constant of excited oxygen $(=\mathrm{O}(1 \mathrm{D}))$ with a $\mathrm{N}_{2}$ or $\mathrm{O}_{2}$ molecule $\left(\mathrm{cm}^{3}\right.$ molecules $\left.{ }^{-1} \mathrm{~s}^{-1}\right) ; k_{\beta}$ is the rate constant of $\mathrm{O}(1 \mathrm{D})$ with $\mathrm{H}_{2} \mathrm{O}\left(\mathrm{cm}^{3}\right.$ molecules $\left.{ }^{-1} \mathrm{~s}^{-1}\right) ; k_{\mathrm{NO} 2}$ is the rate constant of $\mathrm{NO}_{2}$ with the $\mathrm{OH}$ radical; $J_{\mathrm{O} 3}$ and $J_{\mathrm{HCHO}}$ are photolysis rate coefficients estimated by the TUV model on the NCAR website; $M_{\text {air }}$ is the number of molecules of $\mathrm{O}_{2}$ and $\mathrm{N}_{2}$ per $\mathrm{cm}^{3}$ of air; $k_{\mathrm{OH}}$ is the $\mathrm{OH}$ reaction rate constant with terpenes; $k_{\mathrm{O} 3}$ is the $\mathrm{O}_{3}$ reaction rate constant with terpenes $\left(\mathrm{cm}^{3}\right.$ molecules $\left.{ }^{-1} \mathrm{~s}^{-1}\right)$.

2.3.2. Estimation of the Secondary Anthropogenic and Biogenic Contributions to $\mathrm{HCHO}$

Secondary Anthropogenic Contribution

$[\mathrm{HCHO}]_{\text {secondary anthropogenic }}$ cannot be directly quantified using this approach due to its various

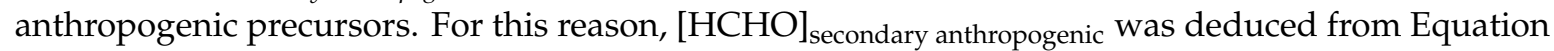
(1) by subtracting all the estimated sources of measured formaldehyde.

$$
\begin{aligned}
{[\mathrm{HCHO}]_{\text {secondary anthropogenic }} } & =\text { Unknown } \\
& =[\mathrm{HCHO}]_{\text {measured }}-[\mathrm{HCHO}]_{\text {primary anthropogenic }} \\
& -[\mathrm{HCHO}]_{\text {primary biogenic }}-[\mathrm{HCHO}]_{\text {secondary biogenic }}
\end{aligned}
$$

This term also includes HCHO from unknown sources (e.g., marine emissions).

Secondary Biogenic Contributions

$[\mathrm{HCHO}]_{\text {biogenic secondary }}$ was estimated from the oxidation of its major biogenic precursors: isoprene and monoterpenes. The term is expressed as (cf. Appendix B):

$$
[\mathrm{HCHO}]_{\text {biogenic secondary }}=[\mathrm{HCHO}]_{\text {isoprene }}+[\mathrm{HCHO}]_{\text {monoterpenes }} .
$$

$[\mathrm{HCHO}]_{\text {isoprene }}$ is calculated as:

$$
[H C H O]_{i s o p r e n e}=\frac{\mathrm{\gamma}_{H C H O}}{\mathrm{\gamma}_{M V K}+\mathrm{\gamma}_{M A C R}} \times[M V K+M A C R]=1.14 \times[M V K+M A C R]
$$

where $\frac{\gamma(H C H O)}{\gamma(M V K)+\gamma(M A C R)}=\frac{0.629}{(0.23+0.32)}=1.14 ; \gamma(H C H O), \gamma(M V K)$, and $\gamma(M A C R)$ are the yields of $\mathrm{HCHO}, \mathrm{MVK}$ and MACR deduced from the reaction of isoprene with the $\mathrm{OH}$ radical, respectively; and. $\backslash[M A C R+M V K]$ is the concentration measured by the PTR-MS $(m / z 71)$.

The equation for $[\mathrm{HCHO}]_{\text {monoterpenes }}$ is:

$$
[\mathrm{HCHO}]_{\text {monoterpenes }}=\frac{\left(\mathrm{X} \times k_{\mathrm{OH}}[\mathrm{OH}]+Y \times k_{\mathrm{O} 3}\left[\mathrm{O}_{3}\right]\right) \times[\text { monoterpenes }]_{t}}{\left(\left(k_{2}-k_{\mathrm{OH}}\right)[\mathrm{OH}]-k_{\mathrm{O} 3}\left[\mathrm{O}_{3}\right]\right)} \times\left(1-e^{\left(\left(k_{\mathrm{OH}}-k_{2}\right)[\mathrm{OH}]+k_{\mathrm{O} 3}\left[\mathrm{O}_{3}\right]\right) t}\right)
$$

where $k_{\mathrm{O} 3}$ and $k_{\mathrm{OH}}$ in $\left(\mathrm{cm}^{3}\right.$ molecules $\left.{ }^{-1} \mathrm{~s}^{-1}\right)$ are the rate constants for the reactions of monoterpenes with $\mathrm{O}_{3}$ and $\mathrm{OH}$, respectively (Appendix $\mathrm{B}$ ); $X$ and $Y$ are the calculated percentages of formation of $\mathrm{HCHO}$ from the reaction of monoterpenes with $\mathrm{OH}$ and $\mathrm{O}_{3}$, respectively; and $t$ is the transport time defined in the next section. 


\subsubsection{Transport Time Estimation}

The aim of this calculation was to consider the depletion of formaldehyde during atmospheric transport. The transformation of $\mathrm{HCHO}$ depends on its origins (biogenic or anthropogenic). Consequently, two methods were used to estimate this transport time: one for anthropogenic emissions and one for biogenic emissions.

\section{Anthropogenic Transport Time}

The urban sites (Le Port and cities around) are $15 \mathrm{~km}$ away from the observatory in a straight line. The anthropogenic transport time in seconds was estimated based on the distance between the source and the measurement point and the wind speed. The anthropogenic transport time is the ratio between the distance and the wind speed at the Maïdo observatory: $t=\frac{d(=15 \mathrm{~km})}{v}=8.7 \times 10^{3}$, on average.

\section{Biogenic Transport Time}

The biogenic transport time was estimated from the reaction of $\mathrm{OH}$ with isoprene and its oxidation products:

$$
\frac{[\mathrm{MVK}]+[\mathrm{MACR}]}{[\text { isoprene }]}=\frac{0,32 \times k_{\text {iso }}}{\left(k_{\text {mvk }}-k_{\text {iso }}\right)} \times\left(1-e^{\left(k_{\text {iso }}-k_{\text {mvk }}\right)[\mathrm{OH}] t}\right)+\frac{0,23 \times k_{\text {iso }}}{\left(k_{\text {macr }}-k_{\text {iso }}\right)} \times\left(1-e^{\left(k_{\text {iso }}-k_{\text {macr }}\right)[\mathrm{OH}] t}\right)
$$

The transport time $t(\mathrm{~s})$ was deduced from the theoretical Equation (10); $k_{i s o}, k_{M A C R}$, and $k_{M V K}$ are the rate constants for the reactions of isoprene, MACR, and MVK with the $\mathrm{OH}$ radical $\left(\mathrm{cm}^{3}\right.$ molecules $\left.{ }^{-1} \mathrm{~s}^{-1}\right)$, respectively.

Appendix B provides an elaborate description of the method.

\subsection{Parameters of the Positive Matrix Factorization}

A second approach to determine the formaldehyde sources is proposed and was compared to the CKB calculation described in Section 2.3. This second approach was based on the PMF mathematical tool used to compensate for the limitation of the first approach. The PMF permits the estimation of the number of VOC source factors and their respective contribution to the total VOC. To this end, the PMF decomposes a matrix into two matrices: the matrix of the factor contribution and the matrix of the factor profile. The number of factors corresponds to the potential sources of VOCs and is attributed by the operator after careful examination of the factor profiles along with the mathematical outputs of the model simulations. Three parameters were studied (Appendix C): the maximal value of residuals mean (IM), the maximal value of residuals standard deviation (IS), and the goodness-of-fit parameter (Q).

More information on the PMF method and its applications to atmospheric issues was provided in Paatero and Tapper [50].

The PMF 5.0 software package (US Environmental Protection Agency, Washington, D.C., USA) was applied on the BIRA PTR-MS data. We used 15 compounds for the study: formaldehyde, methanol, isoprene, acetonitrile, dimethyl sulfide (DMS), acetone, acetic acid, acetaldehyde, methacrolein/methyl vinyl ketone (MACR + MVK), monoterpenes ( $m / z 81$ and $m / z$ 137), methyl ethyl ketone (MEK), benzene, toluene and xylenes. We selected 6-18 April 2018 for the analysis given the lack of cyclones and volcanic eruptions during this period.

Two input files were necessary: one for the measured concentration of the species and one for the estimated concentration uncertainty. The uncertainty $(\sigma)$ corresponding to concentrations lower than the limit of detection (LOD) was equal to $5 / 6 \times \mathrm{DL}$ and the concentration was set to LOD/2. For concentrations above the LOD, $\sigma$ is unchanged. If the concentration is missing, $\sigma$ becomes the average concentration multiplied by 4 [51]. 
Then, the data were clustered into 3 categories: bad, weak, and strong based on the signal to noise ratio (SNR): $\left(\frac{S}{N}\right)_{i}=\sqrt{\frac{\sum_{j=1}^{n}\left(x_{i j}-s_{i j}\right) 2}{\sum_{j=1}^{n} s_{i j}^{2}}}$, where $x$ is the concentrations and $s$ is the uncertainties of the species $j$ for $i$ observations. If the SNR is less than 0.2 , the species was excluded and flagged as "bad"; if the ratio was between 0.2 and 2.0, the species was flagged as "weak" and the uncertainty was multiplied by 4 ; and for SNR $>2.0$, the species was flagged as "strong" and the uncertainty was not changed. The SNR represents the quality of the data reported in Table 2. Table 2 provides important parameters for PMF analysis to establish the status of compounds and to deduce the different sources. Six compounds were assigned a weak status: HCHO, DMS, benzene, toluene, xylenes, and monoterpenes. These values of these components were often below the detection limit (more than $50 \%$ in red in Table 2). The other VOCs (methanol, acetaldehyde, acetonitrile, acetone, acetic acid, and isoprene, and MACR + MVK and MEK) were flagged as strong. Monoterpenes concentrations derived from PTR-MS ion signals at $\mathrm{m} / \mathrm{z} 81$ and from $\mathrm{m} / \mathrm{z} 137$ ion signals were both considered due the difference in SNR (1.2 and 0.7, respectively) and lower percentage of missing values for $\mathrm{m} / \mathrm{z} 81(64 \%)$.

Table 2. Summary of data quality: percentage of values below the limit of detection (LOD), percentage of missing values, signal to noise ratio (SNR), and status attributed at the volatile organic compounds (VOCs) for the positive matrix factorization (PMF) analysis. The red values show the importance of the percentage of values below the LOD and missing values.

\begin{tabular}{ccccc}
\hline Compounds & \% Value $<$ LOD & \% Missing Values & SNR & Status \\
\hline HCHO & $18 \%$ & $5 \%$ & 1.3 & Weak \\
Methanol & $6 \%$ & $6 \%$ & 4.7 & Strong \\
Acetaldehyde & $23 \%$ & $6 \%$ & 3 & Strong \\
Acetonitrile & $0 \%$ & $0 \%$ & 10 & Strong \\
Acetone & $0 \%$ & $6 \%$ & 9.1 & Strong \\
acetic acid & $2 \%$ & $6 \%$ & 7 & Strong \\
Dimethyl Sulfide (DMS) & $84 \%$ & $0 \%$ & 0.4 & Weak \\
Isoprene & $47 \%$ & $0 \%$ & 4.4 & Strong \\
Methacrolein + Methyl Vinyl Ketone & $45 \%$ & $0 \%$ & 4.2 & Strong \\
(MACR + MVK) & $15 \%$ & $0 \%$ & 4.6 & Strong \\
Methyl Ethyl Ketone (MEK) & $69 \%$ & $0 \%$ & 1.2 & Weak \\
Benzene & $64 \%$ & $0 \%$ & 1.2 & Weak \\
Monoterpenes $(m / z$ 81) & $81 \%$ & $0 \%$ & 0.5 & Weak \\
Toluene & $72 \%$ & $0 \%$ & 0.7 & Weak \\
Xylenes & $73 \%$ & $0 \%$ & 0.7 & Weak \\
\hline Monoterpenes $(m / z ~ 137)$ & & &
\end{tabular}

First, several runs were performed with factors ranging from 2 to 8 . The IM, IS, and Q are calculated for each factor to deduce the optimal factor. The value for each factor is presented in Appendix $C$. Then, the optimal number of factors was determined by the largest value of the slope of the curve. In the present case, the shift is provided for $k=4$. The $k-1$ and $k+1$ solutions are also considered. We verified these parameters (correlation between each factor must be small) and carefully examined the atmospheric meaning of the determined source profiles and the optimization of the solution. The Fpeak is a rotational tool that accurately determines the number of optimal factors. $\mathrm{Q}$ was calculated for different Fpeak values: $-1,-0.5,0,0.5$ and 1 . The best solution is found when $\mathrm{Q}$ is minimized [22]. Fpeak here was equal to 0 (Appendix C).

PMF output uncertainties were estimated using three models: base model displacement error estimation (DISP), base model bootstrap error estimation (BS), and the DISP + BS model. These methods were described by Norris et al. [22] and Paatero et al. [52]. DISP was applied resulting in no swaps occurring during the calculation. The 5-factors solution was stable and sufficiently robust. No results were obtained with the BS and DISP + BS models. Standard deviations for the PMF were less than $1 \%$ so they were not relevant in our measures. 


\section{Results}

\subsection{Diurnal Variation in VOC Species}

The average concentration of the main biogenic and anthropogenic VOCs is reported for the three sites in Figure 3. A slight reduction in VOCs concentrations was observed for the Maïdo site, except for isoprene, which is emitted close to the Maïdo observatory by neighboring tamarind forests [29]. The concentrations between the Maïdo observatory and Bélouve were comparable.

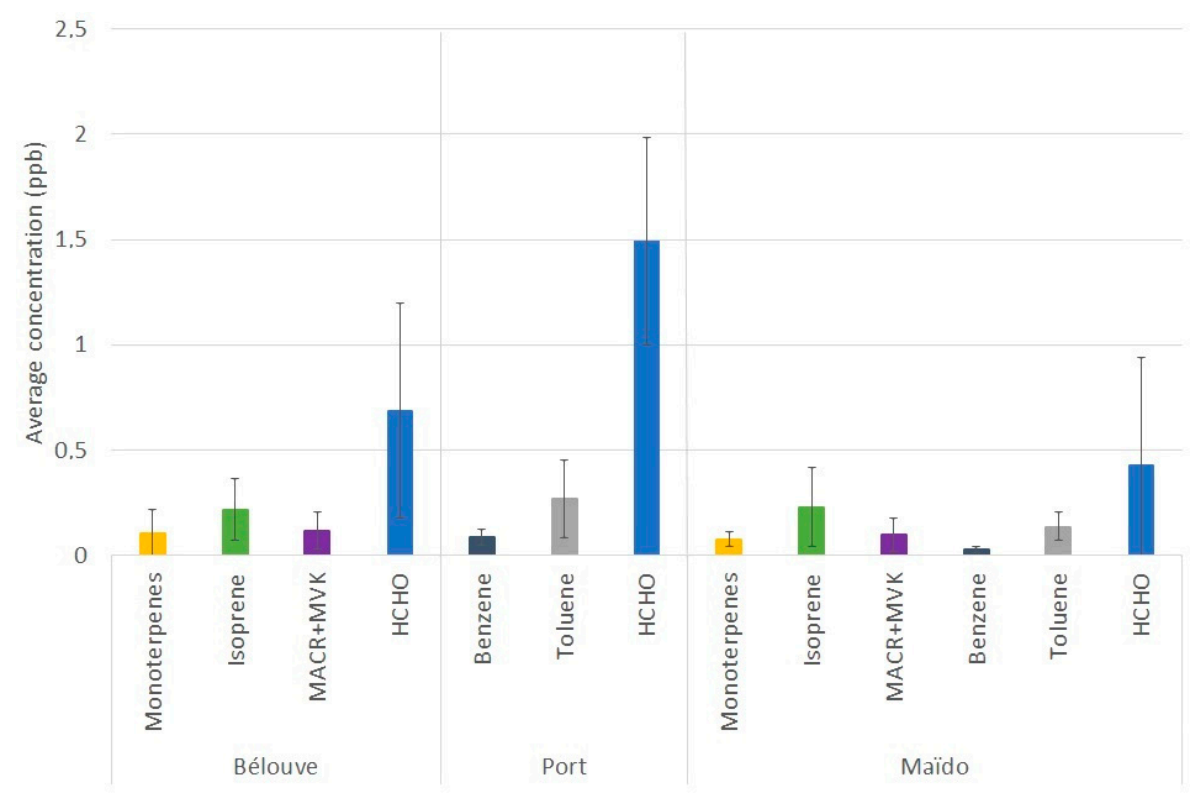

Figure 3. Partitioning of the average concentrations of the main VOCs in ppbv $( \pm 1 \sigma)$ measured in Bélouve forest (from 25 April to 2 May 2018) and Le Port (from 20 April 2018) with the Laboratoire des Sciences, du Climat et de l'Environnement (LSCE) PTR-MS and at the Maïdo observatory (from 7 April to 19 April) with the Royal Belgium Institute for Space Aeronomy (BIRA) PTR-MS, except for the formaldehyde data that were recorded by the Aerolaser (AL 4021 model; Garmisch-Partenkirchen, Germany) instrument.

The time series plots of all parameters measured at Maïdo and Bélouve from 6 April to 2 May 2018 are presented in the Figures 4 and 5. Figure 6A,B depict the diurnal variation at Maïdo and Bélouve from 25 April to 2 May 2018. No diurnal cycle was found for Le Port as few data were obtained resulting from a power failure that occurred during cyclone Fakir.

At 05:00 UT, the wind direction changes (westerly, Figures 4 and 6A) and upslope wind bring air masses from the boundary mixing layer with higher $\mathrm{NO}_{\mathrm{x}}$ values toward Maïdo. At 14:00 UT, the wind direction changes again and the level of boundary mixing layer decreases, so that the Maïdo observatory is then located in free troposphere. 

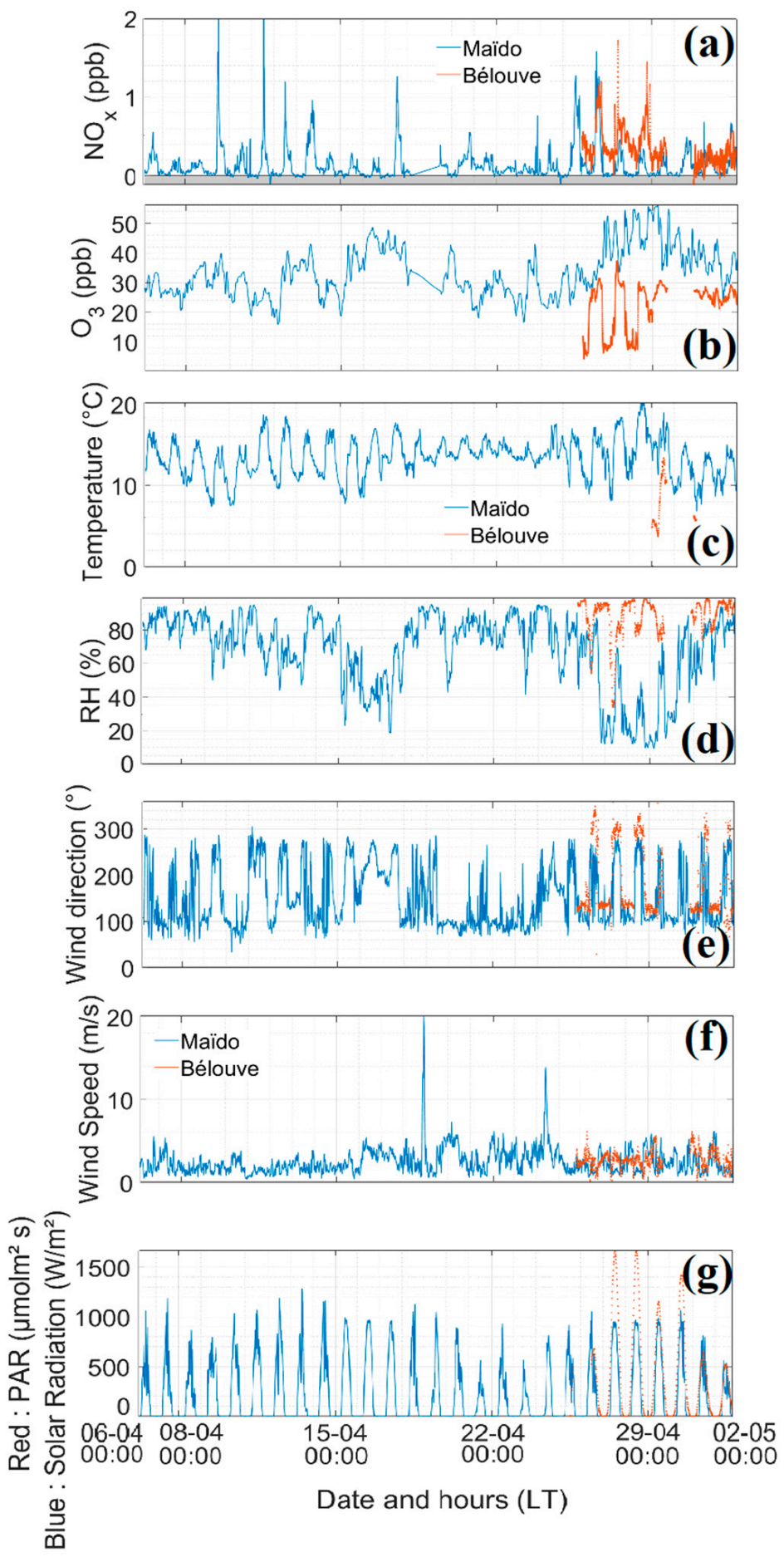

Figure 4. Time series of gases $\left(\mathrm{NO}_{\mathrm{x}}\right.$ and $\left.\mathrm{O}_{3}\right)$, temperature, relative humidity, wind speed and direction and solar radiation parameters from 6 April to 2 May 2018. Blue, Maïdo; orange, Bélouve; LT, local time. (a) Nitrogen oxides $\left(\mathrm{NO}_{\mathrm{x}}, \mathrm{ppb}\right),(\mathbf{b})$ ozone $\left(\mathrm{O}_{3}, \mathrm{ppb}\right),(\mathbf{c})$ Temperature $\left({ }^{\circ} \mathrm{C}\right)$, (d) Relative Humidity $(\mathrm{RH}$, $\%)$, (e) Wind Direction $\left(^{\circ}\right)$, (f) Wind Speed $\left(\mathrm{m} \mathrm{s}^{-1}\right)$, (g) Red: PAR $\left(\mu \mathrm{mol} \mathrm{m} \mathrm{m}^{-2} \mathrm{~s}^{-1}\right)$, Blue: Solar radiation $\left(\mathrm{W} \mathrm{m}^{-2}\right)$. 

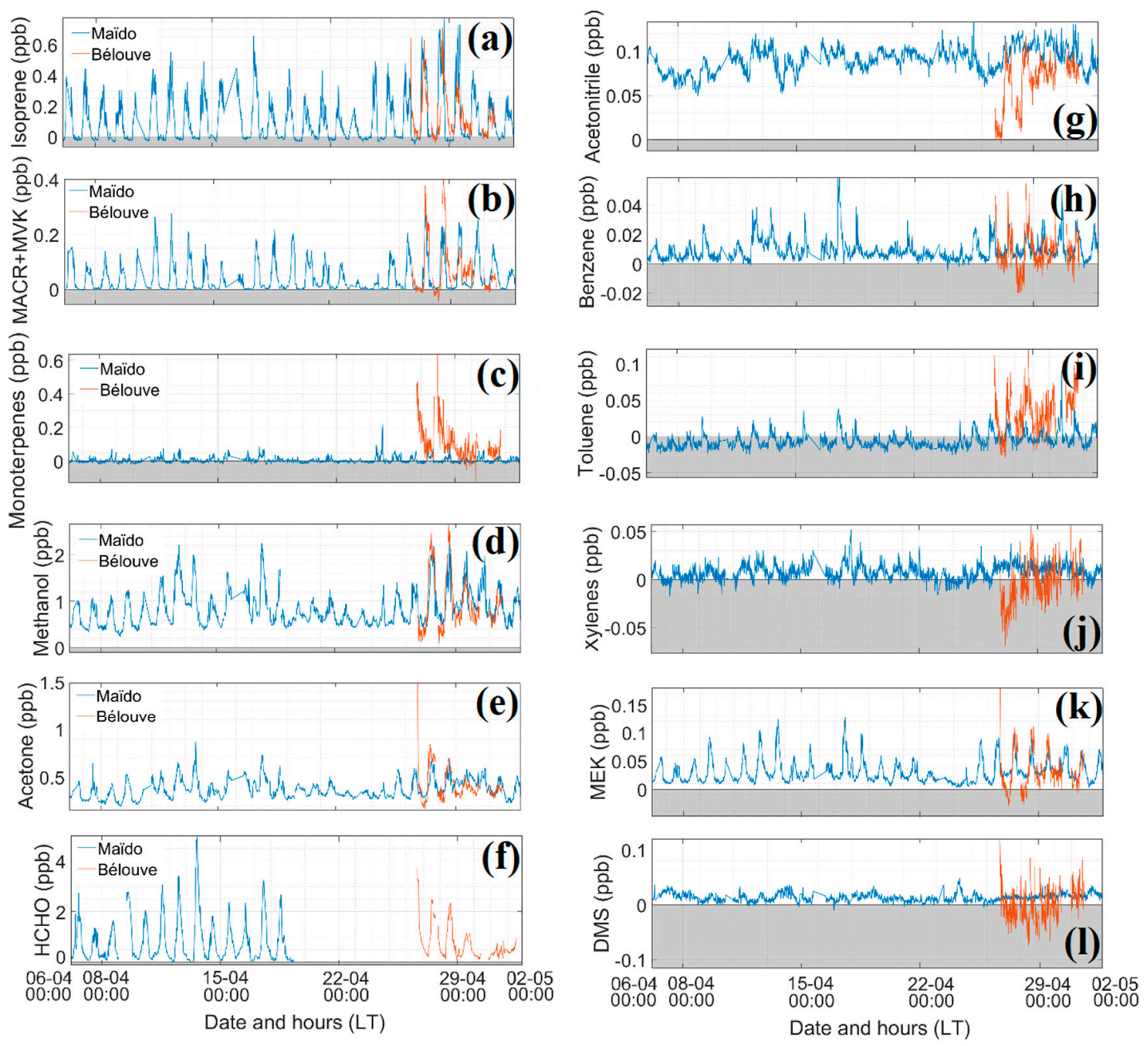

Figure 5. Time series of different VOCs measured by the BIRA PTR-MS at Maïdo and LSCE PTR-MS at Bélouve, except for formaldehyde data, which were measured by the Aerolaser (AL 4021 model; Garmisch-Partenkirchen, Germany) (from 12 March to 19 April 2018 for the Maïdo observatory and 25 April to 2 May for Bélouve). Orange, Bélouve; Maïdo, blue for the same period of 6 April to 2 May 2018. No data were obtained for acetic acid, acetaldehyde, and xylenes Bélouve. Negative concentrations are plotted in grey area. (a) Isoprene (ppb), (b) Methacrolein + Methyl Vinyl Ketone (MACR+MVK, $\mathrm{ppb})$, (c) Monoterpenes (ppb), (d) Methanol (ppb), (e) Acetone (ppb), f. Formaldehyde (HCHO, ppb), (g) Acetonitrile (ppb), (h) Benzene (ppb), (i) Toluene (ppb), (j) Xylenes (ppb), (k) Methyl Ethyl Ketone (MEK, ppb), (l) Dimethyl Sulfide (DMS, ppb).

The diurnal variations in $\mathrm{O}_{3}, \mathrm{NO}_{x}$, and relevant meteorological parameters at Bélouve and Maïdo are presented in Figure 6A. Similar diurnal variations in $\mathrm{NO}_{\mathrm{x}}$ and meteorological parameters were previously measured during the 2015 Forests-gAses-aeRosols-Clouds Exploratory (FARCE) campaign, which was also conducted at the Maïdo observatory and along the Maïdo mountain slopes [29]. At Maïdo during the night, $\mathrm{O}_{3}$ concentrations remain almost constant due to the chemical conditions (no photolysis and low $\mathrm{NO}_{\mathrm{x}}$ conditions) and stable dynamical conditions. The nighttime $\mathrm{O}_{3}$ and $\mathrm{NO}_{\mathrm{x}}$ concentrations represent the free tropospheric background of the subtropical southern hemisphere. This results in an $\mathrm{O}_{3}$ decrease in agreement with the Leighton cycle [53]. $\mathrm{O}_{3}$ is formed by photolysis of $\mathrm{NO}_{2}$ to form $\mathrm{NO}$, and $\mathrm{NO}_{2}$ is formed by the reaction of $\mathrm{O}_{3}$ with $\mathrm{NO} . \mathrm{O}_{3}$ concentration increases during the day resulting from oxidation of VOCs in the presence of NO [54]. At 14:00 UT, wind direction changes again. The Maïdo observatory is then located in the free troposphere under the influence of easterly winds. Ozone increases and reaches the background concentration while VOCs and $\mathrm{NO}_{x}$ decrease. 

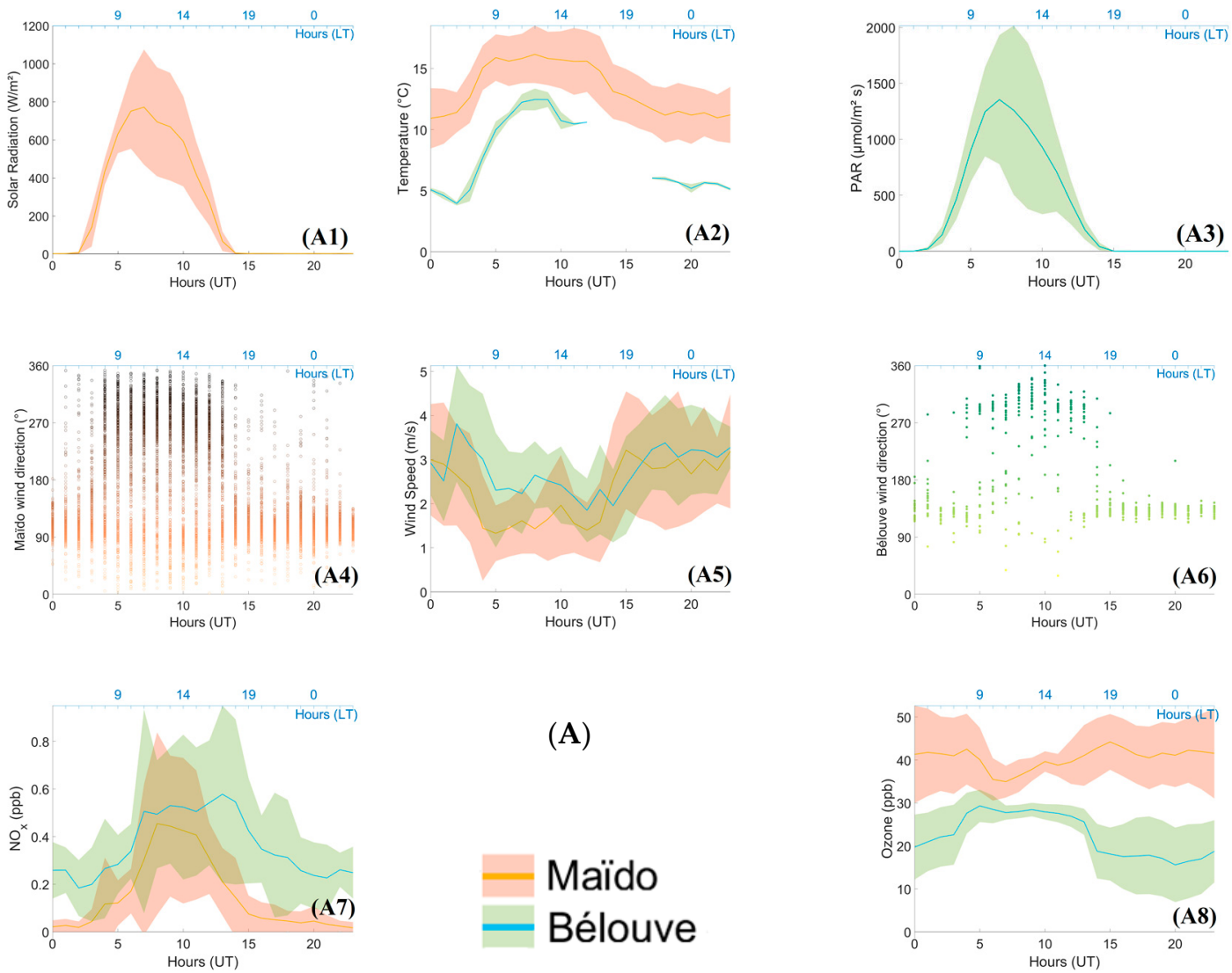

(A)
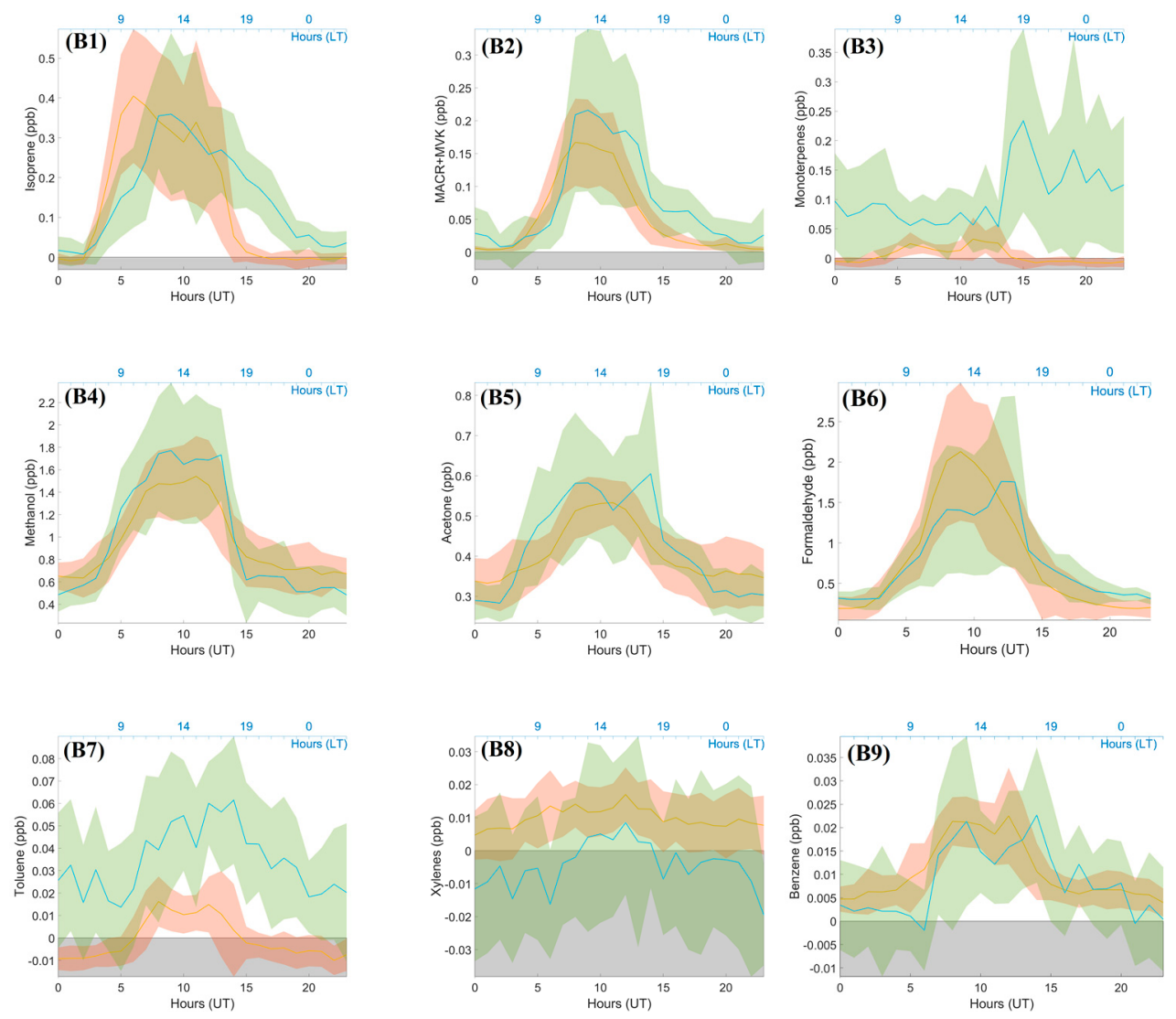

Figure 6. Cont. 

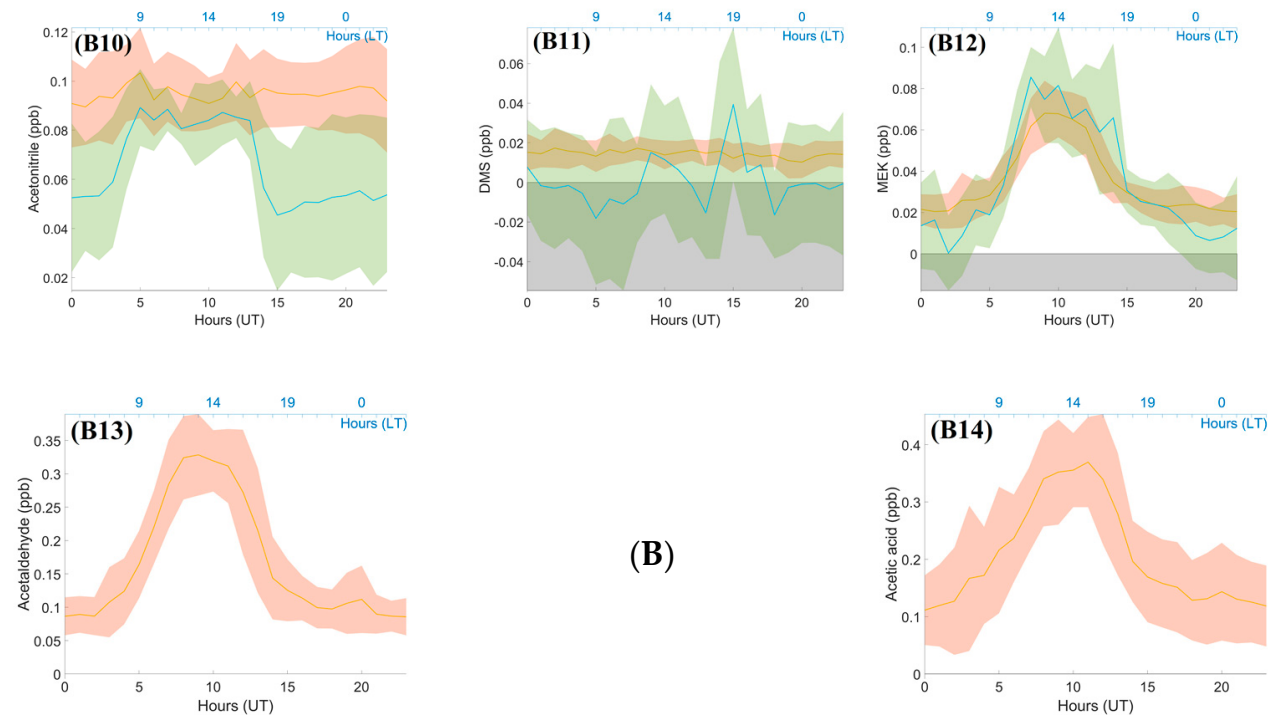

Figure 6. (A) Diurnal variation in gases $\left(\mathrm{NO}_{x}\right.$ and $\left.\mathrm{O}_{3}\right)$, temperature, solar radiation parameters, and wind speed with their standard deviation $(1 \sigma)$ and wind direction at Maïdo and Bélouve for each hour. (A1) Solar Radiation ( $\mathrm{W} \mathrm{m}^{-2}$ ), (A2) Temperature $\left({ }^{\circ} \mathrm{C}\right)$, (A3) PAR ( $\left.\mu \mathrm{mol} \mathrm{m}^{-2} \mathrm{~s}^{-1}\right)$, (A4) Maïdo Wind Direction $\left({ }^{\circ}\right)$, (A5) Wind Speed $\left(\mathrm{m} \mathrm{s}^{-1}\right)$, (A6) Bélouve Wind Direction $\left(^{\circ}\right)$ (A7) Nitrogen oxides $\left(\mathrm{NO}_{\mathrm{x}}\right.$, $\mathrm{ppb})$, (A8) ozone $\left(\mathrm{O}_{3}, \mathrm{ppb}\right)$. (B) Diurnal variations in different VOCs and their standard deviation $(1 \sigma)$, measured by the BIRA PTR-MS at Maïdo and LSCE PTR-MS at Bélouve, except for formaldehyde data, which were measured by the Aerolaser (AL 4021 model; Garmisch-Partenkirchen, Germany) (from 12 March to 19 April for the Maïdo observatory and 25 April to 2 May for Bélouve). Green, Bélouve measurements; red, Maïdo measurements for the same period from 25 April to the 2 May 2018. No data were obtained for acetic acid, acetaldehyde, and xylenes at Bélouve. (B1) isoprene (ppb), (B2) Methacrolein + Methyl Vinyl Ketone (MARC +MVK, ppb), (B3) Monoterpenes (ppb), (B4) Methanol (ppb), (B5) Acetone (ppb), (B6) Formaldehyde (HCHO, ppb), (B7) Toluene (ppb), (B8) Xylenes (ppb), (B9) Benzene (ppb), (B10) Acetonitrile (ppb), (B11) Dimethyl Sulfide (ppb), (B12) Methyl Ethyl Ketone (MEK), (B13) Acetaldehyde (ppb), (B14) Acetic acid (ppb).

At Bélouve, $\mathrm{O}_{3}$ concentrations during the night were lower than at Maïdo due to the lower altitude of the site [28], higher concentrations of NO, ozonolysis of terpenes, and surface deposition [55]. At 04:00 UT, $\mathrm{O}_{3}$ increases due to the influence of the boundary mixing layer and the beginning of photochemical production processes. As a result, almost similar concentrations of $\mathrm{O}_{3}$ at Bélouve and Maïdo were recorded in the morning.

The impact of the Fakir cyclone was observed on measurements from 19 April to 24 April 2018. Temperature and solar radiation decreased, high relative humidity was observed, and the dominant wind was easterly. Two peaks in the wind speed occurred before and at the end of the cyclone (Figure 4). Figure 5 presents the time series of VOCs. Isoprene, MACR + MVK, acetone, and MEK concentrations decreased during the cyclone period. No impact on concentrations was recorded during the volcanic eruptions (27 April to 1 June 2018).

In Figure 5, from 6 April to 2 May 2018, almost all the compounds present diurnal variation and cycle, besides DMS. Negative concentrations (e.g., toluene) occurred when the background measurement was overestimated, as explained in Section 2.2.1. At Maïdo, similar patterns were found, with well-defined diurnal variation for isoprene, MACR + MCK, MEK, methanol, acetone and formaldehyde. The concentrations of these compounds reached a minimum of $0.1 \mathrm{ppb}$ with maximum concentrations of $0.75 \mathrm{ppb}$ for isoprene, $0.27 \mathrm{ppb}$ for MACR + MVK, $0.13 \mathrm{ppb}$ for MEK, $2.3 \mathrm{ppb}$ for methanol, $0.85 \mathrm{ppb}$ for acetone, and $4.3 \mathrm{ppb}$ for formaldehyde. The concentrations remained low for toluene, xylenes, benzene, terpenes, DMS, and acetonitrile with maximum concentrations of $0.03,0.05$, 
$0.05,0.07,0.04$, and $0.13 \mathrm{ppb}$, respectively. The variability of these compounds is further explained below focusing on the daily diurnal variations at Bélouve and Maïdo.

The diurnal variation plots (Figure 6B) can be differentiated into three categories: diurnal variation with one maximum concentration during the day, diurnal variation with two or more concentration peaks, and no diurnal variation. We found no diurnal variation for DMS and acetonitrile. DMS is emitted by phytoplankton over the ocean [56] and its lifetime in the tropical boundary layer is less than one day [57]. The concentrations after transport are low (average $=11.8 \mathrm{ppt}$ ). Acetonitrile is usually a marker of biomass burning [58] with a longer lifetime (1.4 years) [59]. This compound was not influenced by the variations in the boundary layer during the period chosen ( 25 April to 2 May). Figure 5 shows that the variation in acetonitrile concentration remained low (average $=0.1 \mathrm{ppb}$ ).

A large percentage of isoprene is oxidized to form secondary products [60]. Isoprene exhibits a strong diurnal variation where its concentration is the highest during the day (06:00-18:00 UT, $0.4 \pm 0.16 \mathrm{ppb}$ ) and decreases at 10:00 UT, when the MACR and MVK concentrations are at their maximum $(0.17 \pm 0.07 \mathrm{ppb})$. At both sites, isoprene levels were linked to the solar radiation and temperature, which is consistent with previous studies [61], displaying similar diurnal variation between 02:00 and 15:00 UT. This concentration is in agreement with the simulated concentrations by Meso-NH during the FARCE campaign [29]. Several other compounds showed the same diurnal patterns: methanol, MEK, acetone, acetic acid, and acetaldehyde, which are emitted by vegetation and anthropogenic activities. The maximum concentrations of these compounds were $1.54 \pm 0.36$, $0.068 \pm 0.015,0.53 \pm 0.05,0.35 \pm 0.07$, and $0.325 \pm 0.05 \mathrm{ppb}$, respectively. The same diurnal pattern was obtained for different compounds with different lifetimes and photochemical reaction rates. For instance, the lifetime is about 10 days for acetic acid, where $k_{O H}=7.4 \times 10^{-13} \mathrm{~cm}^{3}$ molecule $\mathrm{e}^{-1} \mathrm{~s}^{-1}$, and $8.8 \mathrm{~h}$ for acetaldehyde, where $k_{\mathrm{OH}}=1.5 \times 10^{-11} \mathrm{~cm}^{3}$ molecule $\mathrm{e}^{-1} \mathrm{~s}^{-1}$ ) [62]. Acetone concentrations decline more slowly at the end of the day due to acetone's lower rate constant and longer lifetime (61 days, $k_{\mathrm{OH}}=1.8 \times 10^{-13} \mathrm{~cm}^{3}$ molecule ${ }^{-1} \mathrm{~s}^{-1}$ [62]) compared with the other studied compounds.

The variability in the typical anthropogenic VOCs (xylenes, toluene and benzene, with maximum concentrations of $0.017 \pm 0.009,0.016 \pm 0.007$, and $0.021 \pm 0.005 \mathrm{ppb}$, respectively) exhibited similar patterns. These components are emitted by human activities such as traffic. They show a diurnal variation, but with two peaks, one in the morning and one in the afternoon, which is similar to the diurnal pattern of $\mathrm{NO}_{x}(0.45 \pm 0.38 \mathrm{ppb}$ on average at 08:00 and 13:00 UT). The concentrations were low (a few ppt during the day), e.g., the concentration of benzene was less than $0.03 \mathrm{ppb}$ on average.

The monoterpenes measured at the Maïdo observatory revealed two peaks (07:00 and 14:00 UT). This was not the case for Bélouve measurements; the concentration began to increase at 13:00 UT through the end of the day and the night, when the sink terms were the lowest. As the concentration of monoterpenes was low, the biogenic toluene emission was probably insignificant compared to anthropogenic emissions [43]. The maximal concentration was observed at 15:00. The reactions with $\mathrm{OH}$ and $\mathrm{O}_{3}$ occurring during the day, coupled with mixing and dilution, resulted in a decrease in the concentration of monoterpenes. At Maïdo, the monoterpenes concentrations are very low compared to those at Bélouve because the Bélouve measurements were recorded in a tropical forest that includes plant species with high terpenes emissions, leading to higher concentrations of these compounds.

Methanol and formaldehyde had the highest concentrations of VOCs measured at the Maïdo observatory, with maximum values of $1.54 \pm 0.36$ and $1.76 \pm 0.26 \mathrm{ppb}$ during the day, respectively. These two compounds can be released by both vegetation and anthropogenic activities. The range of formaldehyde concentrations measured at Maïdo was close to those observed at Bélouve and Le Port (1.74 \pm 0.14 and $1.49 \pm 0.24$ ppbv on average, respectively). In March and April 2015, similar concentrations were measured at the Maïdo observatory (1.74 ppb) with maxima between 08:00 and 10:00 $\mathrm{UT}$, reaching up to $\sim 4 \mathrm{ppb}$ [29]. Several studies have reported the diurnal variations of concentrations of formaldehyde at tropical [7,29], background [63], or marine [64] sites. De Blas et al. [65] estimated an average $\mathrm{HCHO}$ of $1.42 \mathrm{ppbv}$ at rural sites and observed diurnal cycles with maximum concentrations 
of up to $4 \mathrm{ppb}$. HCHO levels between 0.5 and $3 \mathrm{ppb}$ were observed in the Amazonian forest [7] and between 1.0 and $13.7 \mathrm{ppbv}$ in urban areas [66].

The maximum concentrations of isoprene, MACR + MVK, and formaldehyde at Bélouve approached to those of Maïdo, but with an offset of a few hours in the peak level. This offset could be due to the circulation pattern on the island, differences in chemical reactions during the transport of air masses at the Maïdo observatory and Bélouve, or local depletion and formation. Further investigation is needed to establish the reason for this offset. Photosynthetically active radiation (PAR) measured at Bélouve had the same pattern as the solar radiation (Figures 4 and 6A) measured at the Maïdo observatory. The temperatures were very different between the two sites: the maximum values were $16 \pm 2{ }^{\circ} \mathrm{C}$ at Maïdo and $13{ }^{\circ} \mathrm{C} \pm 1{ }^{\circ} \mathrm{C}$ at Bélouve and $\sim 20^{\circ} \mathrm{C}$ measured in 2015 [29]. Temperature affects the source of isoprene in the atmosphere; emissions of isoprene are low under cold conditions [67]. The maximum PAR at Bélouve was $1400 \mu \mathrm{mol} \mathrm{s}^{-1} \mathrm{~m}^{-2}$ and displayed a pronounced diurnal variation as already observed by Duflot et al. [29].

The patterns for acetone and methanol concentrations were the same. Higher concentrations were measured at Bélouve than at Maïdo during the day. The strong vegetation emissions explain this difference.

Considering the atmospheric dynamics and circulation patterns on the island, the identification of sources and sinks of these components is necessary to better understand the repartitioning of the VOCs and more particularly HCHO at the Maïdo observatory.

\subsection{Estimation of Formaldehyde Sources with CKB Method}

The concentration of formaldehyde measured at the Maïdo observatory and calculated concentrations for the known part $\left([\mathrm{HCHO}]_{\text {biogenic }}^{\text {primary }},[\mathrm{HCHO}]_{\text {biogenic }}^{\text {secondary }},[\mathrm{HCHO}]_{\text {anthropogenic }}^{\text {primary }}\right.$ ) are presented in Figure 7. We calculated these values for 7 April to 19 April. Negative concentrations were not considered in the calculation.

We observe a strong diurnal variation with a maximum mixing ratio of $1.76 \pm 0.26 \mathrm{ppb}$ at 8:00 UT (Figure 7, blue line). The calculated concentrations were lower than the measured concentrations. Of all potentially contributing terms, $[\mathrm{HCHO}]_{\text {biogenic }}^{\text {secondary }}$ contributed the most, but still only $0.126 \pm 0.04 \mathrm{ppb}$, and showed the same diurnal evolution as the measured formaldehyde concentrations. For $[\mathrm{HCHO}]_{\text {anthropogenic }}^{\text {primary }}$, we found two little peaks: one at 02:00 and the other at approximately at 14:00 UT. Due to the low wind speed conditions $\left(3.3 \mathrm{~m} \mathrm{~s}^{-1}\right.$ on average during the night, Figure $\left.6 \mathrm{~A}\right)$, residues of $\mathrm{HCHO}$ may remain in the free troposphere at the end of the day and overnight. $[\mathrm{HCHO}]_{\text {biogenic }}^{\text {primary }}$ contributed little to the measured formaldehyde during the day. During the night, the concentration increased due to the consideration of terpenes in the calculations. Terpenes are mostly oxidized during daytime and less during the night, so the concentration increases at night.

Only $\sim 9 \%$ corresponded to biogenic emissions and 3\% to primary anthropogenic emissions. The calculated contributions accounted for $89 \%$ of the measured values. The large value of the unknown concentration can be explained by the lack of consideration of secondary anthropogenic formation, marine emissions, and long-range transport in this method. The term $\Psi$ was not estimated in this study. The primary biogenic emission term was not calculated with the value of $\Psi$ measured at Maïdo observatory for tamarind emissions, so the biogenic part may be under- or overestimated. Sensitivity tests were performed. When increasing $\Psi$ by a factor $10,[\mathrm{HCHO}]_{\text {biogenic }}^{\text {primary }}$ increased by $6 \%$ of the calculation and the unknown part reduces to $83 \%$. 
This first approach is based on some relatively simple kinetics hypotheses. Note that atmospheric dynamics were not considered here, and many reactions are missing (e.g., for secondary anthropogenic formation). A high percentage of formaldehyde ( $89 \%$ ) cannot be explained using this method. However, this indicates that the secondary biogenic term contributes more than the primary anthropogenic and biogenic term and has the same pattern as the measured formaldehyde.

PMF analysis was then performed to compare and complement the determination of the sources of formaldehyde.

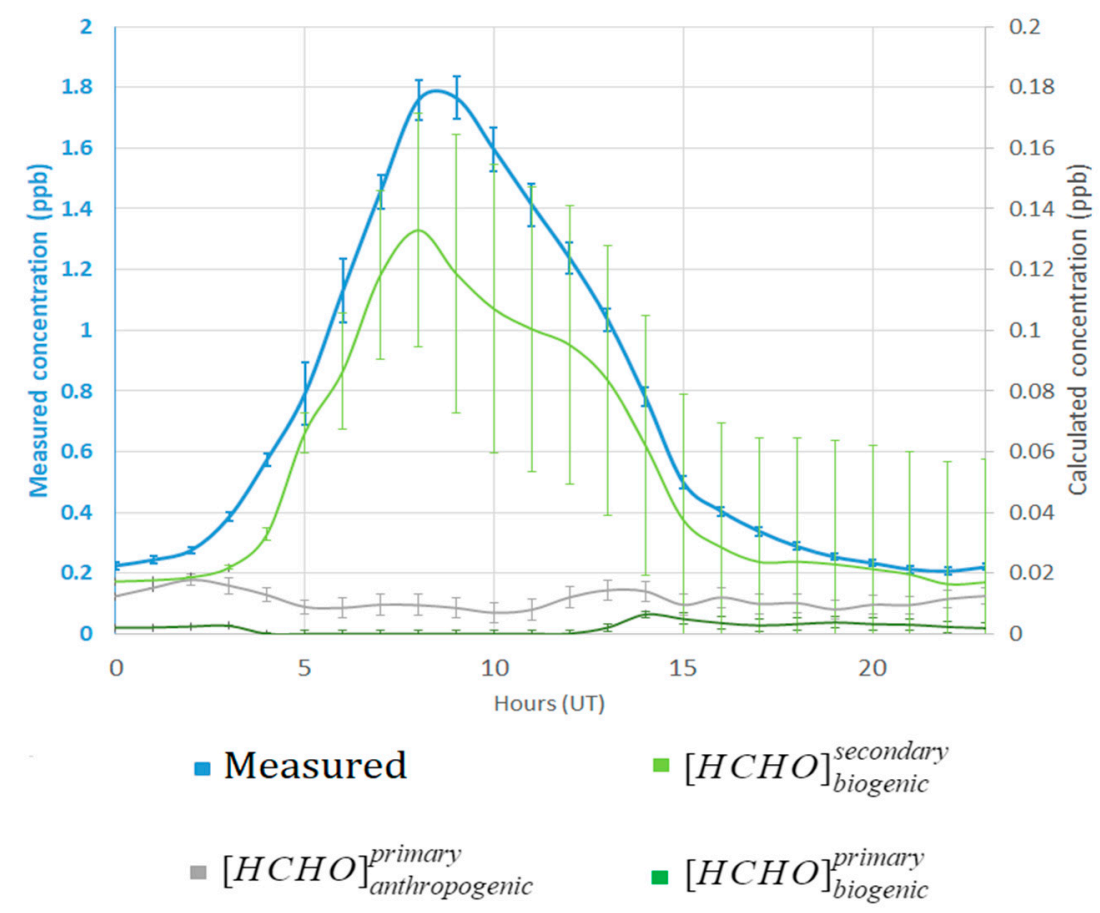

Figure 7. Measured formaldehyde mixing ratio at the Maïdo observatory and mixing ratio of the calculated known sources: primary/secondary biogenic and primary anthropogenic.

\subsection{Positive Matrix Factorization Analysis}

\subsubsection{VOCs Specifications in PMF}

As explained in Section 2.4, five factors were identified by the PMF. The contribution of each factor and their diurnal average concentrations calculated by PMF software (US Environmental Protection Agency, Washington, D.C., USA) are outlined in Figure 8. As with the CKB method, the PMF analysis was applied to 7 April to 18 April.

Table 3 summarizes the correlation of each factor with other parameters: gas concentrations (CO, $\mathrm{NO}_{x}, \mathrm{NO}_{2}, \mathrm{O}_{3}$ ) and meteorological variables (wind speed, wind direction). Wind direction (WD) was divided into two parts: the trade winds $\left(90^{\circ}<\mathrm{WD}<180^{\circ}\right)$ and the westerly winds $\left(200^{\circ}<\mathrm{WD}<315^{\circ}\right)$.

In the first step, we identified the components of each factor that contribute most to the factor. Then, correlations between the factors and the other parameters were studied. Finally, the contributions of these factors/sources were considered for formaldehyde. 
Table 3. Determination coefficients $\left(R^{2}\right)$ between gases and meteorological parameters and factors. Red, strong correlation; black, weak correlation; bold, highest correlation for one parameter; n, number of data used for the correlation.

\begin{tabular}{|c|c|c|c|c|c|}
\hline $\begin{array}{c}\text { Factors } \\
\text { Other } \\
\text { Parameters }\end{array}$ & $\begin{array}{l}\text { F1 Primary } \\
\text { Biogenic } \\
(n=18,919)\end{array}$ & $\begin{array}{c}\text { F2 Secondary } \\
\text { Biogenic } \\
(n=18,919)\end{array}$ & $\begin{array}{c}\text { F3 Primary } \\
\text { Anthropogenic/ } \\
\text { Solvents } \\
(n=18,919)\end{array}$ & $\begin{array}{c}\text { F4 Primary } \\
\text { Anthropogenic/ } \\
\text { Combustion } \\
(n=18,919)\end{array}$ & $\begin{array}{l}\text { F5 Background } \\
\quad(n=18,919)\end{array}$ \\
\hline $\begin{array}{c}\mathrm{CO} \\
(n=17,659)\end{array}$ & 0.27 & 0.23 & 0.35 & 0.52 & 0.18 \\
\hline $\begin{array}{c}\mathrm{NO}_{\mathrm{x}} \\
(n=18,785)\end{array}$ & 0.34 & 0.63 & 0.50 & 0.37 & 0.38 \\
\hline $\begin{array}{c}\mathrm{NO}_{2} \\
(n=18,812)\end{array}$ & 0.27 & 0.58 & 0.52 & 0.34 & 0.38 \\
\hline $\mathrm{O}_{3}(n=17,294)$ & 0.12 & 0.04 & 0.13 & 0.15 & 0.04 \\
\hline $\begin{array}{l}\text { Wind speed } \\
(n=18,638)\end{array}$ & 0.12 & 0.09 & 0.38 & 0.34 & 0.01 \\
\hline $\begin{array}{l}\text { Wind direction } \\
\quad(n=18,638)\end{array}$ & 0.41 & 0.26 & 0.07 & 0.15 & 0.38 \\
\hline $\begin{array}{c}90<\mathrm{WD}<180 \\
(n=7956)\end{array}$ & 0.13 & 0.04 & 0.14 & 0.39 & 0.19 \\
\hline $\begin{array}{c}200<\mathrm{WD}<315 \\
(n=6311)\end{array}$ & 0.14 & 0.32 & 0.12 & 0.04 & 0.09 \\
\hline $\begin{array}{l}\text { Solar radiation } \\
\quad(n=18,638)\end{array}$ & 0.71 & 0.62 & 0.24 & 0.45 & 0.28 \\
\hline $\begin{array}{l}\text { Temperature } \\
(n=18,919)\end{array}$ & 0.63 & 0.64 & 0.35 & 0.51 & 0.14 \\
\hline
\end{tabular}

\subsubsection{Primary Biogenic Factor}

This factor strongly contributed to the biogenic components. Here, isoprene was the main contributor $(92.7 \%$, Figure 8$)$, probably due to local emission of isoprene around the observatory because no strong correlation with $\mathrm{NO}_{\mathrm{x}}$ was observed $\left(R^{2}=0.34\right)$ if we considered that $\mathrm{NO}_{\mathrm{x}}$ concentrations were mixed within the mixing layer and represented the boundary layer height. This factor profile includes methanol, acetone, acetaldehyde, and acetic acid, which are known to have biogenic sources $[5,51]$. This factor is strongly correlated with solar radiation and temperature $[68,69]$, with $R^{2}$ values of 0.71 and 0.63 , respectively. The concentration showed a diurnal cycle that increased from 02:00 UT to reach the maximum concentration at 07:00 UT. The concentration decreased with solar radiation and reached the lowest value at 14:00 UT. This factor is named a primary biogenic factor. The contribution of this factor to the sum of data was $13.8 \%$. 


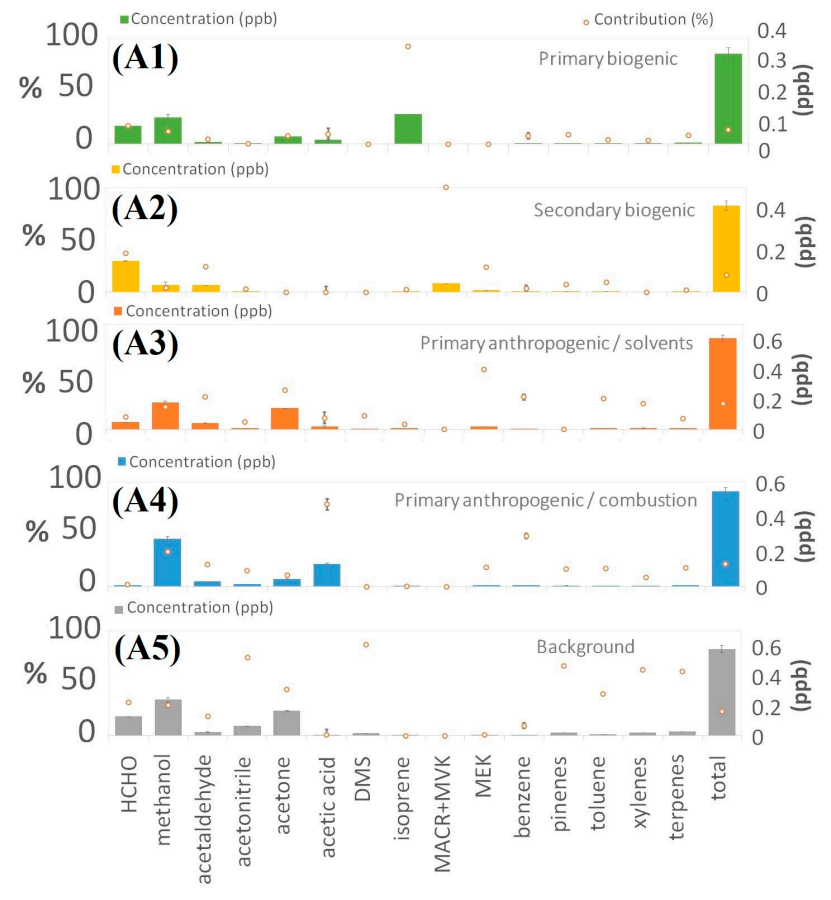

(A)
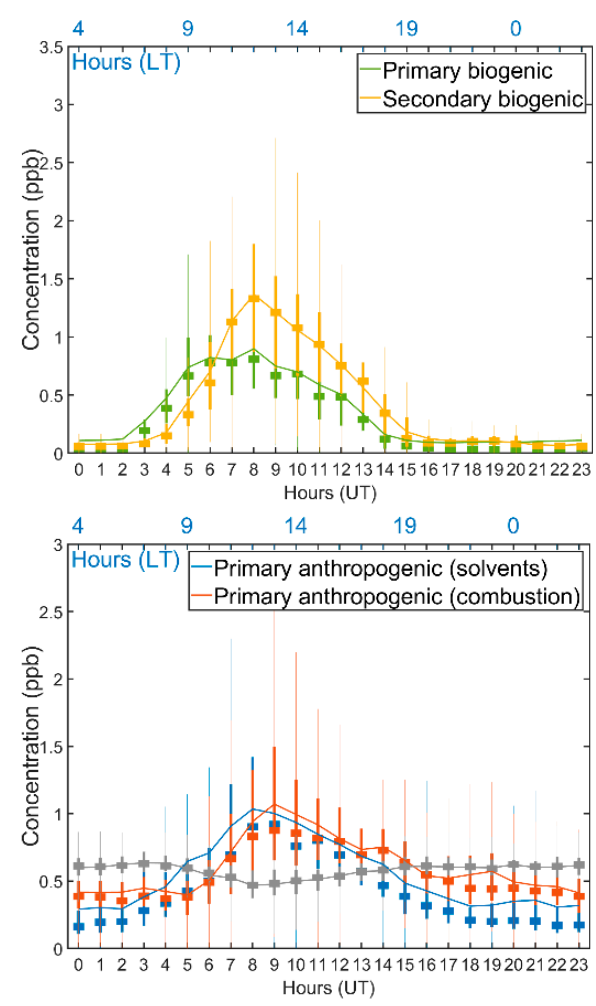

(B)

Figure 8. (A) Concentrations (bar chart) and percentage (orange dots) of the contribution of the five factors and their standard deviation $(1 \sigma)$ provided by the PMF. (A1) Primary biogenic factor, (A2) Secondary biogenic factor, (A3) Primary anthropogenic/solvents factor, (A4) Primary anthropogenic/combustion factor, (A5) Background factor. (B) Daily boxplots of modeled sources from the five-factor solution. Solid line, average concentration is the solid line; squares, medians. The bottom and top edges of the box indicate the 25 th and 75 th percentiles, respectively. The whiskers extend to the most extreme data points.

\subsubsection{Secondary Biogenic Factor}

This factor was characterized by a $100 \%$ contribution of MACR/MVK with a concentration of $0.04 \mathrm{ppb}$ (Figure 8). Methacrolein and methyl vinyl ketone are two products of isoprene oxidation [60]. Formaldehyde is also an oxidation product of isoprene and contributed $37.3 \%(0.15 \mathrm{ppb})$ to this factor. Two other VOCs were included in this factor: acetaldehyde [70] and methyl ethyl ketone (MEK) [71], which contributed $24.5 \%$ and $23.8 \%$, respectively. The term "secondary biogenic" was assigned to this factor. These components present important diurnal variations that follow the rise of the boundary layer at 04:00 UT and have their maximum concentrations at 08:00 UT with variation in $\mathrm{OH}$ concentrations with solar radiation. Table 3 shows that $\mathrm{NO}_{\mathrm{x}}$ is well correlated with this factor $\left(R^{2}=0.63\right)$. This factor is not affected by trade winds $\left(R^{2}=0.04\right)$. The air masses were brought by the west of the Maïdo observatory $\left(R^{2}=0.32\right)$ where a tamarind forest is present. Therefore, influence from local emissions of precursors can be included in this factor, evidenced by the strong correlation with solar radiation $\left(R^{2}=0.62\right)$.

The sum of all compounds was calculated and considered in the PMF analysis. The contribution of this factor was $16.6 \%$ during the selected period to the sum of the data.

\subsubsection{Primary Anthropogenic/Solvents Factor}

The major contributors to this factor were methyl ethyl ketone (MEK) and acetone (57.1\% and $37.2 \%$, respectively). These components are known as solvents emitted by industries or paint $[70,71]$. Acetaldehyde, toluene, and xylenes contributed $31.3 \%, 29.5 \%$, and $24.7 \%$ to this factor, respectively. 
These components are also emitted by fuel combustion [72]. The term "primary anthropogenic/solvent" was used to include the specific type of anthropogenic emissions. They are sourced from the mixed boundary layer. The concentration increased from 05:00 UT onward for three hours after sunrise. No correlation with solar radiation was found. The most correlated parameter was $\mathrm{NO}_{\mathrm{x}}\left(\right.$ was $\left.^{2}=0.50\right)$ due to the common origin of the anthropogenic plume. This factor is well linked with anthropogenic emissions and more particularly with solvents (due to the major contribution of species mentioned before). This factor was the main contributor (24.5\%) of the sum of the data.

\subsubsection{Primary Anthropogenic/Combustion}

This factor is representative of the primary anthropogenic emissions but with a different chemical profile than the preceding factor. Acetic acid and benzene are the components that contributed the most (78.6\% and $48.4 \%$, respectively) to this factor. The factor was named "primary anthropogenic/combustion" due to the presence of components that are emitted by combustion: acetic acid [73], benzene (48.4\%), methanol (33.2\%), acetaldehyde (21.0\%), acetonitrile $(15.2 \%)[59,74]$. This factor was linked with $\mathrm{CO}$ concentration with a strong correlation of 0.52 . We hypothesized that combustion from local pollution due to biomass burning, like barbecues and fuel combustion (traffic), produced these emissions.

This factor varied diurnally with a maximum concentration at 08:00 UT of $1 \mathrm{ppb}$. A slight increase during the night appeared at 21:00 UT. During this period, OVOCs are not oxidized due to lower rate of photochemical reactions and atmospheric dynamics so the concentration rises. This factor contributed $21.9 \%$ to the sum of data.

For both primary anthropogenic factors, the main contributors have a long lifetime; consequently, these two factors are differentiated by chemical species that contribute the most in this factor.

\subsubsection{Background}

The highest contributors to this factor were DMS and acetonitrile with $86.9 \%$ and $74.6 \%$, respectively. The DMS data were flagged as weak and its levels were close to the detection limit. Caution is necessary with such data to not to assign the same importance as strong data. So, other compounds were considered in this study: toluene $(39.9 \%)$, xylenes $(62.9 \%)$, acetone $(44.2 \%)$, methanol $(29.2 \%)$, formaldehyde (32.1\%), and monoterpenes quantified using $m / z 81(66.6 \%)$ and $m / z 137$ (62.9\%) ion signals. No discrepancies were found between $\mathrm{m} / \mathrm{z} 81$ and 137 . They contributed to the same factor despite the slight difference in the SNR and the percentage of lower values. Some of these compounds have a long atmospheric lifetime, e.g., $t_{\text {toluene }}=1.4$ days [54]. However, the background factor showed a slight decrease in concentration during the day, with a minimum at 08:00 UT (0.5 ppb), and high concentrations during the night $(0.6 \mathrm{ppb})$. This dip can be explained by monoterpenes being highly oxidized during the day [75] and their atmospheric residence time is short (nearly one hour). So, this factor reflected the lifetime of certain species that accumulate in the atmosphere and indicated atmospheric background levels (average concentration about $\sim 0.5 \mathrm{ppb}$ ). It also considered the local monoterpene emissions (monoterpenes contributed $62.9 \%$ to this factor). This factor was named "background" and contributed $23.3 \%$ to the sum of data.

No significant correlation was observed with the other parameters.

\subsubsection{HCHO Sources by the PMF}

Each factor is a potential source of formaldehyde. We deduced that $17 \%$ of formaldehyde is formed from primary biogenic emissions, 37.3\% from secondary biogenic formation, $11.6 \%$ from primary anthropogenic/solvent sources, $1.9 \%$ from primary anthropogenic/combustion, and $32.1 \%$ from background. At the local scale, the tamarind forest close to the Maïdo observatory emits a large number of biogenic components that are oxidized. These oxidation processes are the main formation path of formaldehyde. However, formaldehyde is present in the background and contributed in the same order of magnitude as the secondary biogenic factor. The background factor represents of 
long-range transport in the free troposphere, added with local monoterpenes emissions and marine boundary layer sources. Secondary anthropogenic formation was not considered here and could maybe be included in this factor. The formaldehyde contribution to background measurements can correspond to the "unknown" emissions in the kinetics-based calculations.

The PMF considered the relationship between all measured VOCs and atmospheric dynamics through the correlations with the meteorological parameters (wind direction). It is constrained by the nature of the data provided. So, this method overcomes the deficiency the kinetic-based calculation method and $\mathrm{w}$ applicable to the datasets collected during the field campaign.

\section{Discussion and Conclusions}

In this study, we present OVOCs measurements at the Maïdo observatory, Le Port, and Bélouve sites (Reunion Island) during the OCTAVE campaign from March to May 2018. The concentrations of OVOCs presented similar diurnal variation at the Maïdo and Bélouve sites, correlated with the solar radiation and temperature. The range of formaldehyde concentrations measured at the Maïdo observatory $(1.76 \pm 0.26 \mathrm{ppb})$ was the same as at Bélouve and Le Port $(0.74 \pm 0.14$ and $1.49 \pm 0.24 \mathrm{ppbv}$ on average, respectively). The discrepancies can be explained by different meteorological conditions (temperature or solar radiation fluctuations) and type of emissions (biogenic or anthropogenic).

We focused on sources and sinks of formaldehyde ( $\mathrm{HCHO})$ determined from two independent methods: the chemical-kinetics-based (CKB) calculation and positive matrix factorization (PMF) analysis.

The first method suggested four formaldehyde sources: primary biogenic (emissions of $\mathrm{HCHO}$ directly in the atmosphere by biogenic sources), primary anthropogenic (emissions of HCHO directly in the atmosphere from anthropogenic emissions), secondary biogenic (formed by the atmospheric oxidation of biogenic VOCs), and secondary anthropogenic (formed by the atmospheric oxidation of anthropogenic VOCs) sources, the latter being integrated in the unknown term. The calculations indicated that $89 \%$ of formaldehyde is emitted from unknown sources (Figure 7). The unknown term includes many compounds resulting from the oxidation of anthropogenic VOCs and other possible sources of $\mathrm{HCHO}$, such as marine emissions in low concentrations. Calculations for the primary biogenic term were only conducted with monoterpenes, isoprene, and MACR + MVK; the oxidation reactions of many other biogenic components [46] were not considered. The factor $\Psi$ (ratio of formaldehyde to monoterpenes fluxes) produced many uncertainties, implying under- or overestimation of primary biogenic concentrations, even if the primary biogenic emissions are expected to remain low. The correct value of this factor was not determined during the campaign, so we used a literature value, which ranged between 0.02 and 0.2 .

Atmospheric dynamics were not considered; we focused on only the known part: primary biogenic/anthropogenic and secondary biogenic sources. We inferred $8 \%$ (corresponding to $1 \%$ of the total part) for primary biogenic, $67 \%$ (corresponding to $8 \%$ of the total part) for secondary biogenic and $25 \%$ (corresponding to $3 \%$ of the total part) for primary anthropogenic sources (Figure 9). The known part is dominated by secondary biogenic formation. Formaldehyde is preferentially formed by oxidation of biogenic VOCs. 


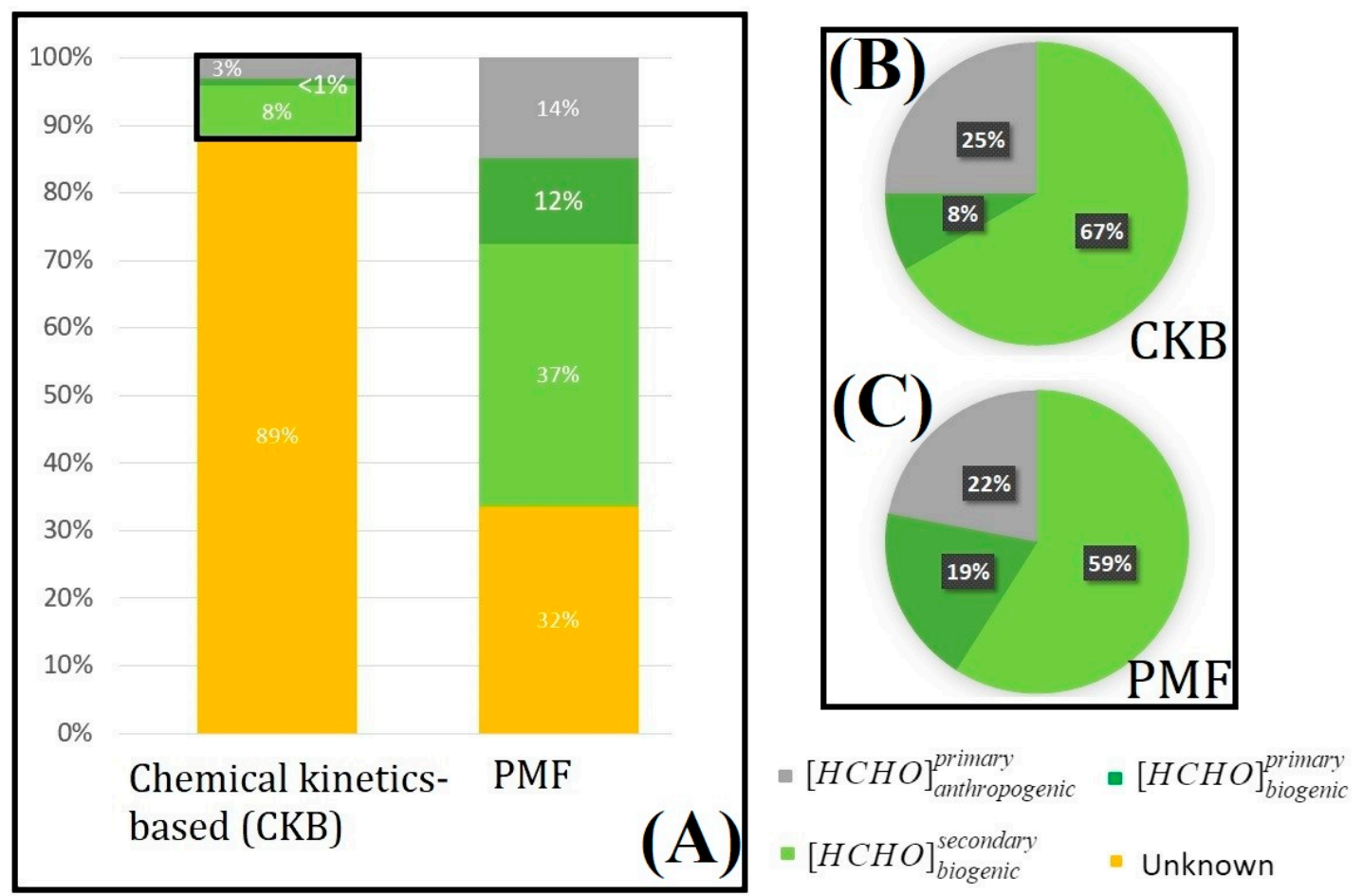

Figure 9. (A) Estimation of formaldehyde sources at the Maïdo site with CKB and PMF analysis. Percentages in pie chart format for the known part for (B) CKB and (C) PMF.

PMF was used to complement and verify these results. Five factors were found to quantify the different contributions to the total VOC concentrations: primary biogenic $(13.8 \%)$, providing a major contribution of isoprene; secondary biogenic $(16.6 \%)$, which represent the emissions due to the oxidation of biogenic VOCs; primary anthropogenic/solvents $(24.5 \%)$, with a high contribution of solvent (acetone and MEK); primary anthropogenic/combustion (21.9\%), which produces a high level of combustion components (acetic acid and benzene); and background (23.3\%) factors, which includes no important contributing species and presents no diurnal variation. We then focused on formaldehyde: $37.3 \%$ of formaldehyde is formed by secondary biogenic formation. Via oxidation of VOCs such as isoprene, $11.6 \%$ from primary anthropogenic/solvent sources, $\mathrm{HCHO}$ is emitted in the atmosphere like a solvent, $17 \%$ from primary biogenic sources (directly by the leaves of plants), $1.9 \%$ from primary anthropogenic/combustion sources. $\mathrm{HCHO}$ is formed by biomass burning and anthropogenic combustion and $32.1 \%$ was associated with the background factor. The background factor considers long-range emissions, marine components, and maybe secondary anthropogenic formation such as the "unknown" emissions calculated by the CKB calculation method. Formaldehyde emissions are well explained by the PMF, which is constrained by the nature of the components in the analysis. For both methods, regarding the known part, the largest source of formaldehyde is the oxidation of VOCs, and particularly the secondary biogenic part (67\% with CKB method and 59\% for PMF).

To conclude, the PMF analysis and CKB calculation can be used complementarily to provide information on formaldehyde sources. The CKB method is based on chemical equations and PMF is a mathematical solver that distributes compounds according to different factors without considering chemistry).

In the future, a more precise determination of the factor $\Psi$ could be considered to more accurately quantify the isoprene emissions of Reunion forest and more particularly by the tamarind species, which is the major tree species around the Maïdo observatory.

This work can be further completed using a more complex and complete chemical model. The Cloud Explicit Physico-chemical Scheme (CLEPS) model could be used to obtain VOCs data to 
simulate (with kinetic chemical reactions as used in the calculation method) the chemistry with a box model [76]. This method considers more kinetic chemical reactions and reduces uncertainties. This model will be completed by the development of a future version of LACYTRAJ initialized with high-resolution wind fields (for example, Weather Research Forecasting (WRF) or Meso-NH models). It could provide a more precise estimation of the fluxes and transport processes of gaseous constituents in mountainous environments.

Finally, the BIO-MAIDO campaign in March and April 2019 will provide new VOC measurements from different locations on Reunion Island with online and offline instruments. The aim of this campaign is to study the cloud formation in air masses during transport from the mountain base to the Maïdo site, providing new measurements of formaldehyde under the same conditions as during the OCTAVE campaign. This campaign will permit a better understanding of cloud formation and the multiphase chemistry in the clouds.

Supplementary Materials: Available online: VAISAILA specificities, https://www.vaisala.com/sites/default/files/ documents/HMP45AD-User-Guide-U274EN.pdf, (accessed on 19 July 2019). NCAR; https://www2.acom.ucar. edu/modeling/tropospheric-ultraviolet-and-visible-tuv-radiation-model, (accessed on 19 July 2019).

Author Contributions: Conceptualization, M.R., J.-L.B., and A.C.; formal analysis, M.R.; investigation, M.R.; resources, M.R, C.A., A.C., V.G., R.S.-E., P.T., V.D., J.B., A.B., J.-M.M, J.-M.P., and L.B.; data curation, M.R, C.A., C.G, N.S., and G.P.; writing-original draft preparation, M.R.; writing—review and editing, M.R, J.-L.B., A.C., C.A., and B.V.; visualization, M.R.; supervision, M.R., J.-L.B., and A.C. All authors have read and agreed to the published version of the manuscript.

Funding: This study was supported by the project OCTAVE of the Belgian Research Action through Interdisciplinary 5 Networks (BRAIN-be) research program (2017-2021) through the Belgian Science Policy Office (BELSPO) under the contract number BR/175/A2/OCTAVE.

Acknowledgments: We thank BIRA for sharing the PTR-MS data to perform PMF and VOCs analyses. We thank LSCE for the formation and the loan of PTR-MS. We acknowledge the European Communities, the Région Réunion, CNRS, and Université de la Réunion for their support and contributions in the construction phase of the research infrastructure OPAR (Observatoire de Physique de l'Atmosphère de La Réunion). OPAR is presently funded by CNRS (INSU), Météo France and Université de La Réunion and managed by OSU-R (Observatoire des Sciences de l'Univers de La Réunion, UMS 3365). Thanks to Douard J.B. for designing and adapting the IGN map for Figure 1. Thanks to Maija Peltola for proofreading the English.

Conflicts of Interest: The authors declare no conflict of interest.

\section{Appendix A Uncertainties Calculation}

\section{Appendix A.1 Estimation of PTR-MS Uncertainties}

\section{Appendix A.1.1 BIRA PTR-MS}

VOC concentrations were obtained by dividing the background-subtracted normalized VOC product ion count rates in normalized counts per second (ncps) by the specific VOC calibration coefficient (ncps/ppbv). Normalized VOC product ion count rates $\left(\mathrm{I}_{\mathrm{VOC}}\right.$, ncps $)$ refer to product ion count rates ( $\mathrm{I}_{\mathrm{VOC}, \text { ncps }}$ ) that would be obtained for a $\mathrm{H}_{3} \mathrm{O}^{+}$source ion count rate of $10^{6}$, i.e., $\mathrm{I}_{\mathrm{VOC}, \mathrm{ncps}}$ $=10^{6} \times\left(\mathrm{I}_{\mathrm{VOC}, \mathrm{ncps}} /\left(500 \times \mathrm{I}_{\mathrm{m} 21, \mathrm{cps}}\right)\right)$. This normalization allows us to consider variations in the ion source production and is common practice in PTR-MS analysis. Errors on the measured counts (Poisson-distributed) for the individual ion species were included to calculate the statistical uncertainties of the individual VOC concentrations. Systematic errors on the mixing ratios were close to $5 \%$ for the compounds that were present in the calibration bottle, and $25 \%$ for acetic acid, the quantification of which was based on calculated ion/molecule $\mathrm{H}_{3} \mathrm{O}^{+}$/acetic acid rate constants and product ion distributions taken from the literature.

VOC detection limits were defined as 3 times the standard error on the background normalized VOC product ion count rates divided by the respective calibration coefficients. 


\section{Appendix A.1.2 LSCE PTR-MS}

The uncertainties were estimated similarly to Baudic et al. [74]:

$$
\sigma_{i}=\sqrt{\left(u \times C_{i}\right)^{2}+(0.5 \times L O D)^{2}}
$$

where $u=\frac{s}{x}$ is the reproducibility calculated from PTR-MS calibration at $2 \mathrm{ppb}, s$ is the standard deviation calculated with the background signal, $x$ is the average concentration, LOD is the limit of detection mentioned previously for each compound, and $C_{i}$ is the mixing ratio for a compound $i$. The detection limits (LOD) were calculated as 3 times the standard error of the background.

Appendix A.2 Estimation of Aerolaser Uncertainties

The uncertainty was estimated by

$$
\sigma_{i}=\sqrt{\left(\frac{D L}{3}+u \times C_{i}\right)^{2}+\left(k \times C_{i}\right)^{2}}
$$

where $L O D=150 \mathrm{ppt}$, the repeatability $u=5 \%$, and $k=2 \times u_{\text {standard }}$ is the expanded uncertainty.

The term $u_{\text {standard }}$ is the uncertainty of the standard. The calculations of $u_{\text {accuracy }}, u_{\text {repeatability, }}$ and $u_{\text {resolution }}$ are based on a standard solution of $30 \mu \mathrm{g} / \mathrm{L}$ within a formaldehyde mass of $m_{\mathrm{HCHO}}=7.5 \times 10^{-6} \mathrm{~g}$.

$$
\begin{gathered}
u_{\text {accuracy }}^{2}=\left(\frac{0.01 \times m_{\mathrm{HCHO}}}{\sqrt{3}}\right)^{2}=4.33 \times 10^{-8} \mathrm{~g} \\
u_{\text {repeatability }}=u_{\text {resolution }}=5 \% \times m_{\mathrm{HCHO}}=3.75 \times 10^{-7} \mathrm{~g}
\end{gathered}
$$

So, $\mathrm{u}_{\text {standard }}=3.85 \times 10^{-7} \mathrm{~g}$ and $k=7.70 \times 10^{-7} \mathrm{~g}$. The expanded uncertainty is $10.3 \%$.

\section{Appendix B Chemical-Kinetics-Based Calculation for Formaldehyde Sources}

Appendix B.1 Estimation of Primary and Anthropogenic/Biogenic Sources of HCHO

Appendix B.1.1 Anthropogenic Emissions

$[\mathrm{HCHO}]_{\text {primary anthropogenic }}$ is the primary anthropogenic contribution of $\mathrm{HCHO}$. This term was deduced using toluene as an anthropogenic tracer. The formula is the result of chemical kinetic equations:

$$
\begin{aligned}
\text { Toluene }+\mathrm{OH} \rightarrow & \text { products }\left(k_{1}=5.96 \times 10^{-12} \mathrm{~cm}^{3} \text { molecules }^{-1} \mathrm{~s}^{-1}\right) \\
\mathrm{HCHO}+\mathrm{OH} \rightarrow & \text { products }\left(k_{2}=9.77 \times 10^{-12} \mathrm{~cm}^{3} \text { molecules }^{-1} \mathrm{~s}^{-1}\right) \\
& \mathrm{HCHO}+h v \rightarrow \mathrm{HCO}+\mathrm{H}\left(\mathrm{JHCHO}_{1}\right) \\
& \mathrm{HCHO}+h v \rightarrow \mathrm{H}_{2}+\mathrm{CO}\left(\mathrm{HCHO}_{2}\right)
\end{aligned}
$$

Using the chemical degradation equation, we obtain

$$
\begin{gathered}
\frac{d[\text { toluene }]}{d t}=-k_{1} \times[\text { toluene }] \times[\mathrm{OH}] \\
\frac{d[\mathrm{HCHO}]}{d t}=-k_{2} \times[\mathrm{HCHO}] \times[\mathrm{OH}]-J_{\mathrm{HCHO}} \times[\mathrm{HCHO}] .
\end{gathered}
$$

Integrating these equations produces

$$
[\text { toluene }]_{t}=[\text { toluene }]_{0} \times e^{-k_{1}[\mathrm{OH}] t}
$$




$$
[\mathrm{HCHO}]_{t}=[\mathrm{HCHO}]_{0} \times e^{\left(-k 2[\mathrm{OH}]-J_{\mathrm{HCHO}}\right) t}
$$

We deduced

$$
\frac{[\mathrm{HCHO}]_{t}}{[\text { toluene }]_{t}}=\frac{[\mathrm{HCHO}]_{0}}{[\text { toluene }]_{0}} \times e^{\left(\left(k_{1}-k 2\right)[\mathrm{OH}]-J_{\mathrm{HCHO}}\right) t}
$$

We obtained

$$
[\mathrm{HCHO}]_{t}=[\mathrm{HCHO}]_{\text {primary anthropogenic }}=\rho \times[\text { toluene }] t \times e^{\left((k 1-k 2)[\mathrm{OH}]-J_{\mathrm{HCHO}}\right) t}
$$

where $\rho=\frac{[\mathrm{HCHO}]_{0}}{[\text { toluene }]_{0}}$ is 5 molecules $\mathrm{cm}^{-3}$ as recorded by Zhang et al. [66] in Beijing and $\rho=4.5 \pm 0.8$ in this study, which is the ratio of formaldehyde concentration to toluene concentration in urban sites; $t$ is the biogenic atmospheric transport time in seconds; $k_{1}$ and $k_{2}$ are formaldehyde and toluene constant reactivity with the $\mathrm{OH}$ radical, respectively [66]; $[\mathrm{OH}]$ is the concentration of $\mathrm{OH}$ radicals, whose principal source is traffic (Section 3.3.3):

$$
[\mathrm{OH}] \times t=\frac{\ln \left(\frac{[\text { toluene }]}{3 \times[\text { benzene }]}\right)}{\left(k_{\text {benzene }}-k_{1}\right)}
$$

where $k_{1}=5.96 \times 10^{-12} \mathrm{~cm}^{3}$ molecules ${ }^{-1} \mathrm{~s}^{-1}$ and $k_{\text {benzene }}=1.23 \times 10^{-12} \mathrm{~cm}^{3}$ molecules $^{-1} \mathrm{~s}^{-1}$; $J_{\mathrm{HCHO}}\left(=J_{\mathrm{HCHO} 1}+J_{\mathrm{HCHO} 2}\right)$ is the photolysis rate of formaldehyde deduced by the tropospheric and ultraviolet-visible radiation (TUV) model on the National Center for Atmospheric Research website (NCAR).

Appendix B.1.2 Biogenic Emissions

The primary biogenic term of $\mathrm{HCHO}$ was deduced from the constant of photolysis and from the oxidation equations of formaldehyde.

$$
\begin{gathered}
\mathrm{HCHO}+\mathrm{OH} \rightarrow \text { products, }\left(k_{2}=9.77 \times 10^{-12} \mathrm{~cm}^{3} \text { molecules }^{-1} \mathrm{~s}^{-1}\right) \\
\text { HCHO }+h v \rightarrow \text { products, }\left(J_{\mathrm{HCHO}}\right)
\end{gathered}
$$

We considered the reaction of monoterpenes with the $\mathrm{OH}$ radical and $\mathrm{O}_{3}$ :

$$
\begin{gathered}
\alpha \text {-pinene }+\mathrm{OH} \rightarrow \text { products, } k_{a}=55.0 \times 10^{-12} \mathrm{~cm}^{3} \text { molecules }{ }^{-1} \mathrm{~s}^{-1} \\
\beta \text {-pinene }+\mathrm{OH} \rightarrow \text { products, } k_{b}=80.2 \times 10^{-12} \mathrm{~cm}^{3} \text { molecules }{ }^{-1} \mathrm{~s}^{-1} \\
\text { Myrcene }+\mathrm{OH} \rightarrow \text { products, } k_{c}=215 \times 10^{-12} \mathrm{~cm}^{3} \text { molecules }{ }^{-1} \mathrm{~s}^{-1} \\
\text { Sabinene }+\mathrm{OH} \rightarrow \text { products, } k_{d}=117 \times 10^{-12} \mathrm{~cm}^{3} \text { molecules }{ }^{-1} \mathrm{~s}^{-1} \\
\text { Limonene }+\mathrm{OH} \rightarrow \text { products, } k_{e}=171 \times 10^{-12} \mathrm{~cm}^{3} \text { molecules }{ }^{-1} \mathrm{~s}^{-11} \\
\text { nes }+\mathrm{OH} \rightarrow \text { products, } k_{\mathrm{OH}}=\% \alpha \text {-pinene } \times k_{a}+\% \beta \text {-pinene } \times k_{b}+\% \mathrm{~m} y \\
\times k_{c}+\% \text { sabinene } \times k_{d}+\% \text { limonene } \times k_{e} \\
\alpha \text {-pinene }+\mathrm{O}_{3} \rightarrow \text { products, } k_{a^{\prime}}=8.63 \times 10^{-17} \mathrm{~cm}^{3} \text { molecules }{ }^{-1} \mathrm{~s}^{-1} \\
\beta \text {-pinene }+\mathrm{O}_{3} \rightarrow \text { products, } k_{b^{\prime}}=1.5 \times 10^{-17} \mathrm{~cm}^{3} \text { molecules }{ }^{-1} \mathrm{~s}^{-1} \\
\text { Myrcene }+\mathrm{O}_{3} \rightarrow \text { products, } k_{c^{\prime}}=47.6 \times 10^{-17} \mathrm{~cm}^{3} \text { molecules }{ }^{-1} \mathrm{~s}^{-1} \\
\text { Sabinene }+\mathrm{O}_{3} \rightarrow \text { products, } k_{d^{\prime}}=8.27 \times 10^{-17} \mathrm{~cm}^{3} \text { molecules }^{-1} \mathrm{~s}^{-1} \\
\text { Limonene }+\mathrm{O}_{3} \rightarrow \text { products, } \mathrm{k}_{\mathrm{e}^{\prime}}=19.8 \times 10^{-17} \mathrm{~cm}^{3} \text { molecules }^{-1} \mathrm{~s}^{-1}
\end{gathered}
$$


Monoterpenes $+\mathrm{O}_{3} \rightarrow$ products, $k_{\mathrm{O} 3}=\% \alpha$-pinene $\times k_{a^{\prime}}+\% \beta$-pinene $\times k_{b^{\prime}}+\%$ myrcene $\times k_{c^{\prime}}+\%$ sabinene $\times k_{d^{\prime}}+\%$ limonene $\times k_{e^{\prime}}$

$k_{a}, k_{b}, k_{c}, k_{d}$, and $k_{e}$ are reported in Table A1 for the calculation of $k_{\mathrm{OH}}$ and $k_{\mathrm{O} 3}$. The percentages of $\alpha$-pinene, $\beta$-pinene, myrcene, sabinene, and limonene were calculated with the concentration measurements of these compounds.

Table A1. Constants of reactivity with $\mathrm{OH}$ and $\mathrm{O}_{3}$ and calculated $k$ for reaction of monoterpenes with $\mathrm{OH}$ radical and $\mathrm{O}_{3}$.

\begin{tabular}{ccc}
\hline Constants $\left(\mathbf{c m}^{\mathbf{3}} \cdot\right.$ molecules $\left.^{-\mathbf{1}} \cdot \mathbf{s}^{-\mathbf{1}}\right)$ & Reaction with $\mathbf{O H}$ & Reaction with $\mathbf{O}_{\mathbf{3}}$ \\
\hline$k_{a}$ & $55.0 \times 10^{-12}$ & $8.63 \times 10^{-17}$ \\
$k_{b}$ & $80.2 \times 10^{-12}$ & $1.5 \times 10^{-17}$ \\
$k_{c}$ & $215 \times 10^{-12}$ & $47.6 \times 10^{-17}$ \\
$k_{d}$ & $117 \times 10^{-12}$ & $8.27 \times 10^{-17}$ \\
$k_{e}$ & $171 \times 10^{-12}$ & $19.8 \times 10^{-17}$ \\
$k$ (calculated) & $k_{\mathrm{OH}}=1.625 \times 10^{-12}$ & $k_{\mathrm{O} 3}=2.586 \times 10^{-16}$ \\
\hline
\end{tabular}

With this chemical kinetic equation, we obtained

$$
\begin{gathered}
\frac{d[\mathrm{HCHO}]}{d t}=-k_{2} \times[\mathrm{HCHO}] \times[\mathrm{OH}]-J_{\mathrm{HCHO}} \times[\mathrm{HCHO}] \\
\frac{d[\text { monoterpenes }]}{d t}=-k_{\mathrm{OH}} \times[\text { monoterpenes }] \times[\mathrm{OH}]-k_{\mathrm{O} 3} \times[\text { monoterpenes }] \times\left[\mathrm{O}_{3}\right]
\end{gathered}
$$

The integrating of these equations gives

$$
\begin{aligned}
{[\text { monoterpenes }]_{t} } & =[\text { monoterpenes }]_{0} \times e^{\left(-k_{\mathrm{OH}}[\mathrm{OH}]-k_{03}[\mathrm{O} 3]\right) t} \\
{[\mathrm{HCHO}]_{t} } & =[\mathrm{HCHO}]_{0} \times e^{\left(-k_{2}[\mathrm{OH}]-J_{\mathrm{HCHO}}\right) t}
\end{aligned}
$$

Then,

$$
\frac{[\mathrm{HCHO}]_{t}}{[\text { monoterpenes }]_{t}}=\frac{[\mathrm{HCHO}]_{0}}{[\text { monoterpenes }]_{0}} \times e^{\left(\left(k_{\mathrm{OH}}-k_{2}\right)[\mathrm{OH}]-k_{\mathrm{O} 3}\left[\mathrm{O}_{3}\right]-J_{\mathrm{HCHO}}\right) t} .
$$

The primary biogenic $\mathrm{HCHO}$ was estimated as follows:

$$
[\mathrm{HCHO}]_{\text {primary biogenic }}=\psi \times[\text { terpenes }]_{t} \times e^{\left(\left(k_{\mathrm{OH}^{-}}-k_{2}\right)[\mathrm{OH}]+k_{\mathrm{O} 3}[\mathrm{O} 3]-J_{\mathrm{HCHO}}\right) t}
$$

where $\Psi=\frac{[\mathrm{HCHO}]_{0}}{[\text { monoterpenes }]_{0}}=0.129[49]$, which is the formaldehyde concentration to monoterpenes concentration ratio determined by the plant emissions; $t$ is biogenic transport time in seconds.

$[\mathrm{OH}]$ is the concentration in molecules $\mathrm{cm}^{-3}$. The $\mathrm{OH}$ concentration was deduced by considering the biogenic sources:

$$
[\mathrm{OH}]=\frac{2 \times J_{\mathrm{HCHO}} \times[\mathrm{HCHO}]+J_{\mathrm{O} 3} \times \frac{k_{\beta}}{k_{\alpha}} \times \frac{\left[\mathrm{O}_{3}\right] \times\left[\mathrm{H}_{2} \mathrm{O}\right]}{M_{\text {air }}}}{k_{\mathrm{NO} 2} \times\left[\mathrm{NO}_{2}\right]} .
$$

With $\mathrm{HCHO}, \mathrm{NO}_{2}$, and $\mathrm{O}_{3}$ concentrations, $\mathrm{OH}$ reactivity being constant with $\mathrm{O}_{3}\left(k_{\alpha}\right.$ and $\left.k_{\beta}\right)$ and $\mathrm{NO}_{2}\left(k_{\mathrm{NO}}\right)$, the molecules number of $\mathrm{N}_{2}$ and $\mathrm{O}_{2}$ per $\mathrm{cm}^{-3}$ of air, $J_{O}$, and $J_{H C H O}$ constants deduced by TUV model, $M_{\text {air }}$ is the number of molecules of $\mathrm{O}_{2}$ and $\mathrm{N}_{2}$ per $\mathrm{cm}^{3}$ of air. $k_{2}$ and $k_{\mathrm{OH}}$ are the $\mathrm{OH}$ reaction rate constants and $k_{\mathrm{O} 3}$ is the reaction rate constant of terpenes. 
Appendix B.2 Estimation of Secondary and Anthropogenic/Biogenic Sources of HCHO

Appendix B.2.1 Anthropogenic Emissions

The secondary anthropogenic $\mathrm{HCHO}$ could not be quantified because several compounds can form formaldehyde. So, it was deduced with

$$
\begin{gathered}
{[\mathrm{HCHO}]_{\text {secondary anthropogenic }}=[\mathrm{HCHO}]_{\text {measured }}-[\mathrm{HCHO}]_{\text {primary anthropogenic }}} \\
=-[\mathrm{HCHO}]_{\text {primary biogenic }}-[\mathrm{HCHO}]_{\text {secondary biogenic. }}
\end{gathered}
$$

Appendix B.2.2 Biogenic Emissions

The secondary biogenic term of $\mathrm{HCHO}$ was estimated from the contribution of isoprene and monoterpenes oxidation. The term is expressed as follows:

$$
[\mathrm{HCHO}]_{\text {biogenic secondary }}=[\mathrm{HCHO}]_{\text {isoprene }}+[\mathrm{HCHO}]_{\text {monoterpenes. }}
$$

To calculate the term $[\mathrm{HCHO}]_{\text {isoprene, }}$ we used percentages of isoprene oxidation product from Carter and Atkinson [77] with the isoprene oxidation reaction:

$$
\mathrm{OH}+\text { isoprene } \rightarrow 0.629 \mathrm{HCHO}+0.23 \mathrm{MACR}+0.32 \mathrm{MVK}+\text { products. }
$$

If considering all formaldehyde is formed by the isoprene oxidation, the equation is

$$
[H C H O]_{\text {isoprene }}^{\text {secondary biogenic }}=\frac{\mathrm{\gamma}_{H C H O}}{\mathrm{\gamma}_{M V K}+\mathrm{\gamma}_{M A C R}} \times[M V K+M A C R]=1.14 \times[M V K+M A C R]
$$

With $\left.\frac{\gamma(H C H O)}{\gamma(M V K)+\gamma(M A C R)}=\frac{0.629}{(0.23+0.32)}=1.14, \gamma_{(H C H O}\right), \gamma_{(M V K)}$, and $\gamma_{(M A C R)}$, we determined the yields of $\mathrm{HCHO}, \mathrm{MVK}$, and MACR.

The second term, $[\mathrm{HCHO}]$ monoterpenes, was calculated as follows. The reactions are the same for deducing $[\mathrm{HCHO}]_{\text {biogenic }}^{\text {primary }}$ but we consider $\mathrm{HCHO}$ yields from Atkinson and Arey [46]:

$$
\begin{gathered}
\mathrm{HCHO}+\mathrm{OH} \rightarrow \text { products, } k_{2}=9.77 .10^{-12} \mathrm{~cm}^{3} \text { molecules }^{-1} \mathrm{~s}^{-1} \\
\alpha \text {-pinene }+\mathrm{OH} \rightarrow 0.19 \mathrm{HCHO}+\text { products, } k_{a}=55.0 \times 10^{-12} \mathrm{~cm}^{3} \text { molecules }^{-1} \mathrm{~s}^{-1} \\
\beta \text {-pinene }+\mathrm{OH} \rightarrow 0.45 \mathrm{HCHO}+\text { products, } k_{b}=80.2 \times 10^{-12} \mathrm{~cm}^{3} \text { molecules }^{-1} \mathrm{~s}^{-1} \\
\text { Myrcene }+\mathrm{OH} \rightarrow 0.30 \mathrm{HCHO}+\text { products, } k_{c}=215 \times 10^{-12} \mathrm{~cm}^{3} \text { molecules }^{-1} \mathrm{~s}^{-1} \\
\text { Sabinene }+\mathrm{OH} \rightarrow 0 \mathrm{HCHO}+\text { products, } k_{d}=117 \times 10^{-12} \mathrm{~cm}^{3} \text { molecules }^{-1} \mathrm{~s}^{-1} \\
\text { Limonene }+\mathrm{OH} \rightarrow 0 \mathrm{HCHO}+\text { products, } k_{e}=171 \times 10^{-12} \mathrm{~cm}^{3} \text { molecules }^{-1} \mathrm{~s}^{-1} \\
\text { Monoterpenes }+\mathrm{OH} \rightarrow \mathrm{X} \mathrm{HCHO}+\text { products }\left(k_{\mathrm{OH}}\right) \text { with } \mathrm{X}=\% \alpha \text {-pinene } \times 0.19 \\
+\% \beta \text {-pinene } \times 0.45+0.3 \times \% \text { myrcene }+0 \times \% \text { sabinene }+0 \times \% \text { limonene } \\
\alpha \text {-pinene }+\mathrm{O}_{3} \rightarrow 0.22 \mathrm{HCHO}+\text { products, } k_{a^{\prime}}=8.63 \times 10^{-17} \mathrm{~cm}^{3} \text { molecules }{ }^{-1} \mathrm{~s}^{-1} \\
\beta \text {-pinene }+\mathrm{O}_{3} \rightarrow 0.76 \mathrm{HCHO}+\text { products, } k_{b^{\prime}}=1.5 \times 10^{-17} \mathrm{~cm}^{3} \text { molecules }^{-1} \mathrm{~s}^{-1} \\
\text { Myrcene }+\mathrm{O}_{3} \rightarrow 0.26 \mathrm{HCHO}+\text { products, } k_{c^{\prime}}=47.6 \times 10^{-17} \mathrm{~cm}^{3} \text { molecules } \mathrm{s}^{-1} \\
\text { Sabinene }+\mathrm{O}_{3} \rightarrow 0 \mathrm{HCHO}+\text { products, } k_{d^{\prime}}=8.27 \times 10^{-17} \mathrm{~cm}^{3} \text { molecules }{ }^{-1} \mathrm{~s}^{-1} \\
\text { Limonene }+\mathrm{O}_{3} \rightarrow 0.15 \mathrm{HCHO}+\text { products, } k_{e^{\prime}}=19.8 \times 10^{-17} \mathrm{~cm}^{3} \text { molecules }{ }^{-1} \mathrm{~s}^{-1} \\
\text { Monoterpenes }+\mathrm{O}_{3} \rightarrow Y \mathrm{HCHO}+\text { products }\left(\mathrm{k}_{\mathrm{O} 3}\right) \text { with } Y=\% \alpha \text {-pinene } \times 0.22 \\
+\% \beta \text {-pinene } \times 0.76+0.26 \times \% \text { myrcene }+0 \times \% \text { sabinene }+0.15 \times \% \text { limonene }
\end{gathered}
$$


With calculation, we obtained: $X=0.56$ and $Y=0.84$.

Equations were obtained:

$$
\begin{gathered}
\frac{d[\text { monoterpenes }]}{d t}=-k_{\mathrm{OH}} \times[\text { monoterpenes }] \times[\mathrm{OH}]-k_{\mathrm{O} 3} \times[\text { monoterpenes }] \times\left[\mathrm{O}_{3}\right] \\
\frac{d[\mathrm{HCHO}]}{d t}=[\text { monoterpenes }] \times\left(k_{\mathrm{OH}} \times \mathrm{X} \times[\mathrm{OH}]+Y \times k_{\mathrm{O} 3} \times\left[\mathrm{O}_{3}\right]\right)-k_{2} \times[\mathrm{HCHO}] \times[\mathrm{OH}]
\end{gathered}
$$

Integrating gave

$$
[\mathrm{HCHO}]=\frac{[\text { monoterpenes }]_{0} \times\left(k_{\mathrm{OH}} \times \mathrm{X} \times[\mathrm{OH}]+Y \times k_{\mathrm{O} 3} \times\left[\mathrm{O}_{3}\right]\right)}{\left(k_{2}-k_{\mathrm{OH}}\right) \times[\mathrm{OH}]-k_{\mathrm{O} 3} \times\left[\mathrm{O}_{3}\right]} \times\left(e^{\left(k_{\mathrm{OH}}[\mathrm{OH}]-k_{\mathrm{O} 3}[\mathrm{O} 3]\right) t}-e^{-k_{2}[\mathrm{OH}] t}\right) .
$$

The equation became

$$
[\mathrm{HCHO}]_{\text {monoterpenes }}=\frac{\left(\mathrm{X} \times k_{\mathrm{OH}}[\mathrm{OH}]+Y \times k_{\mathrm{O}_{3}}\left[\mathrm{O}_{3}\right]\right) \times[\text { monoterpenes }]_{t}}{\left(\left(k 2-k_{\mathrm{OH}}\right)[\mathrm{OH}]-k_{\mathrm{O}}\left[\mathrm{O}_{3}\right]\right)} \times\left(1-e^{\left(\left(k_{\mathrm{OH}}-k_{2}\right)[\mathrm{OH}]+k_{\mathrm{O} 3}\left[\mathrm{O}_{3}\right]\right) t}\right) .
$$

Appendix B.3 Transport Time Estimation

Appendix B.3.1 Anthropogenic Transport Time

The transport time of anthropogenic species was estimated from the ratio between the distance of the source and the wind speed.

Appendix B.3.2 Biogenic Transport Time

Stroud et al. [78] plotted the kinetic curve of MVK/isoprene and MACR/isoprene to deduce the photochemical age using the $\frac{[M V K]+[M A C R]}{[\text { isoprene }]}$ ratio.

With isoprene and products of isoprene oxidation [77]

$$
\begin{gathered}
\mathrm{OH}+\text { isoprene } \rightarrow 0.23 \mathrm{MACR}+0.32 \mathrm{MVK}+\text { products with } k_{\text {iso }}=1 \times 10^{-10} \mathrm{~cm}^{3} \text { molecules }^{-1} \mathrm{~s}^{-1} . \\
\mathrm{MACR}+\mathrm{OH} \rightarrow \text { products with } k_{M A C R}=3.3 \times 10^{-11} \mathrm{~cm}^{3} \text { molecules }^{-1} \mathrm{~s}^{-1} \\
\mathrm{MVK}+\mathrm{OH} \rightarrow \text { products with } k_{M V K}=1.9 \times 10^{-11} \mathrm{~cm}^{3} \text { molecules }^{-1} \mathrm{~s}^{-1}
\end{gathered}
$$

We obtained

$$
\frac{[M V K]+[M A C R]}{[\text { isoprene }]}=\frac{0,32 \times k_{i s o}}{\left(k_{\text {mvk }}-k_{\text {iso }}\right)} \times\left(1-e^{\left(k_{\text {iso }}-k_{\text {mok }}\right)[\mathrm{OH}] t}\right)+\frac{0,23 \times k_{\text {iso }}}{\left(k_{\text {macr }}-k_{\text {iso }}\right)} \times\left(1-e^{\left(k_{\text {iso }}-k_{\text {macr }}\right)[\mathrm{OH}] t}\right) \text {. }
$$

The transport time of biogenic species was deduced from the calculated $[\mathrm{OH}]_{\text {biog }}$ (Appendix B.4.2). The kinetic curve was plotted and the theoretical ratio was deduced.

Appendix B.4 OH Radical Concentration

\section{Appendix B.4.1 Anthropogenic Emissions}

We used measurements of toluene and benzene. With oxidation reactions with the $\mathrm{OH}$ radical, we deduced the product $[\mathrm{OH}] \times t$. The transport time $t$ calculation was presented in Section 3.3.2.

Oxidation reactions of benzene and toluene are

$$
\begin{gathered}
\text { Toluene }+\mathrm{OH} \rightarrow \text { products, } \mathrm{k}_{1}=5.96 \times 10^{-12} \mathrm{~cm}^{3} \text { molecules }{ }^{-1} \mathrm{~s}^{-1} \\
\text { Benzene }+\mathrm{OH} \rightarrow \text { products, } \mathrm{k}_{\text {benzene }}=1.23 \times 10^{-12} \mathrm{~cm}^{3} \text { molecules }^{-1} \mathrm{~s}^{-1}
\end{gathered}
$$


We obtained

$$
\begin{gathered}
\frac{d[\text { toluene }]}{d t}=-k_{1} \times[\text { toluene }] \times[\mathrm{OH}] \\
\frac{d[\text { benzene }]}{d t}=-k_{\text {benzene }} \times[\text { benzene }] \times[\mathrm{OH}]
\end{gathered}
$$

The integration produces

$$
\begin{gathered}
{[\text { toluene }]_{t}=[\text { toluene }]_{0} \times e^{-k_{1}[\mathrm{OH}] t}} \\
{[\text { benzene }]_{t}=[\text { benzene }]_{0} \times e^{-k_{\text {benzene }}[\mathrm{OH}] t}}
\end{gathered}
$$

The ratio gives

$$
\frac{[\text { toluene }]}{[\text { benzene }]}=\frac{[\text { toluene }]_{0}}{[\text { benzene }]_{0}} \times e^{\left(k_{\text {benzene }}-k_{1}\right)[\mathrm{OH}] t}
$$

The ratio $\frac{[\text { toluene }]_{0}}{[\text { benzene }]_{0}}=3$ in urban areas [45], giving

$$
[\mathrm{OH}] \times t=\frac{\ln \left(\frac{[\text { toluene }]}{3 \times[\text { benzene }]}\right)}{\left(k_{\text {benzene }}-k_{1}\right)}
$$

Appendix B.4.2 Biogenic Emissions

To estimate $\mathrm{OH}$ radical concentration, we used photolysis and oxidation equations:

$$
\begin{gathered}
\mathrm{HCHO}+\mathrm{hv} \rightarrow \mathrm{H}+\mathrm{HCO}, \mathrm{J}_{\mathrm{HCHO}}: \text { photolysis constant of } \mathrm{HCHO} \\
\mathrm{H}+\mathrm{O}_{2}+\mathrm{M} \rightarrow \mathrm{HO}_{2}+\mathrm{M} \\
\mathrm{HCO}+\mathrm{O}_{2} \rightarrow \mathrm{HO}_{2}+\mathrm{CO} \\
\mathrm{HO}_{2}+\mathrm{NO} \rightarrow \mathrm{OH}+\mathrm{NO}_{2}
\end{gathered}
$$

The $\mathrm{OH}$ formation from $\mathrm{HCHO}$ is

$$
\begin{gathered}
\frac{d[\mathrm{OH}]_{H C H O}}{d t}=2 \times J_{H C H O} \times[\mathrm{HCHO}] \\
\mathrm{O}_{3}+\mathrm{hv} \rightarrow \mathrm{O}_{2}+\mathrm{O}(1 \mathrm{D}), J_{\mathrm{O}}: \text { photolysis constant of } \mathrm{O}_{3} \\
\mathrm{O}(1 \mathrm{D})+\mathrm{M}_{\mathrm{air}} \rightarrow \mathrm{O}(3 \mathrm{P})+\mathrm{M}_{\mathrm{air}}, k_{\alpha}: 4 \times 10^{-11} \mathrm{~cm}^{3} \text { molecules }^{-1} \mathrm{~s}^{-1} \\
\mathrm{O}(1 \mathrm{D})+\mathrm{H}_{2} \mathrm{O} \rightarrow 2 \mathrm{OH}, k_{\beta}: 2.07 \times 10^{-10} \mathrm{~cm}^{3} \text { molecules }^{-1} \mathrm{~s}^{-1}
\end{gathered}
$$

The $\mathrm{OH}$ formation from $\mathrm{O}_{3}$ is

$$
\frac{d[\mathrm{OH}]_{\mathrm{O} 3}}{d t}=\frac{k_{\beta}}{k_{\alpha}} \times J_{\mathrm{O}_{3}} \times \frac{\left[\mathrm{O}_{3}\right] \times\left[\mathrm{H}_{2} \mathrm{O}\right]}{M_{\text {air }}}
$$

where $M_{\text {air }}$ is the number of molecules of $\mathrm{N}_{2}$ and $\mathrm{O}_{2}$ per $\mathrm{cm}^{3}$.

$$
\mathrm{NO}_{2}+\mathrm{OH} \rightarrow \mathrm{HNO}_{3}, \mathrm{k}_{\mathrm{NO} 2}: 1.2 \times 10^{-11} \mathrm{~cm}^{3} \text { molecules }^{-1} \mathrm{~s}^{-1}
$$

The consumption of $\mathrm{OH}$ by $\mathrm{NO}_{2}$ is

$$
\frac{d[\mathrm{OH}]_{\mathrm{NO} 2}}{d t}=k_{\mathrm{NO}_{2}} \times\left[\mathrm{NO}_{2}\right] \times[\mathrm{OH}] .
$$


Then, we obtain the following from Equation (5):

$$
[\mathrm{OH}]=\frac{2 \times J_{\mathrm{HCHO}} \times[\mathrm{HCHO}]+2 \times J_{\mathrm{O} 3} \times \frac{k_{\beta}}{k_{\alpha}} \times \frac{\left[\mathrm{O}_{3}\right] \times\left[\mathrm{H}_{2} \mathrm{O}\right]}{M_{\text {air }}}}{k_{\mathrm{NO} 2} \times\left[\mathrm{NO}_{2}\right]}
$$

\section{Appendix C Determination of the Optimal Factor with the PMF Analysis}

From the $\mathrm{Q}\left(=\sum_{i=1}^{n} \sum_{j=1}^{m}\left[\frac{x_{i j}-\sum_{k=1}^{p} g_{i k} f_{k j}}{u_{i j}}\right]^{2}\right)$ value with $i$-many samples, $j$ chemical species, $u$ uncertainties, $p$ number of factors, $f$ factor profile of each source, and $g$ factor contribution, IM and IS are determined for 2 to 8 factors (Figure A1). The optimal factor is determined when the slope is broken. In this study, the step was used for four factors. The correlation between each factor and DISP showed that the optimal solution was five factors.
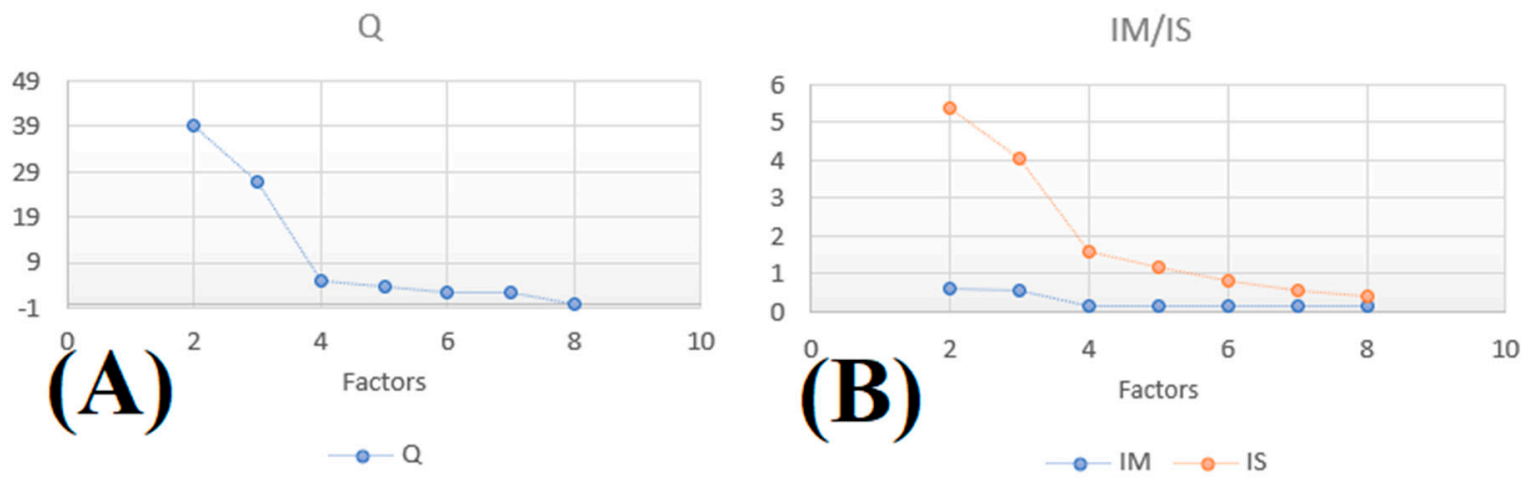

Figure A1. Determination of optimal factor with the (A) residual sum of squares $Q,(B)$ maximal mean of residual (IM), and maximal standard deviation of residual (IS).

Fpeak was studied for five factors. The five values used were $-1,-0.5,0,0.5$, and 1 (Figure A2). The best solution is achieved where $\mathrm{Q}$ is minimized; here, Fpeak was 0 .

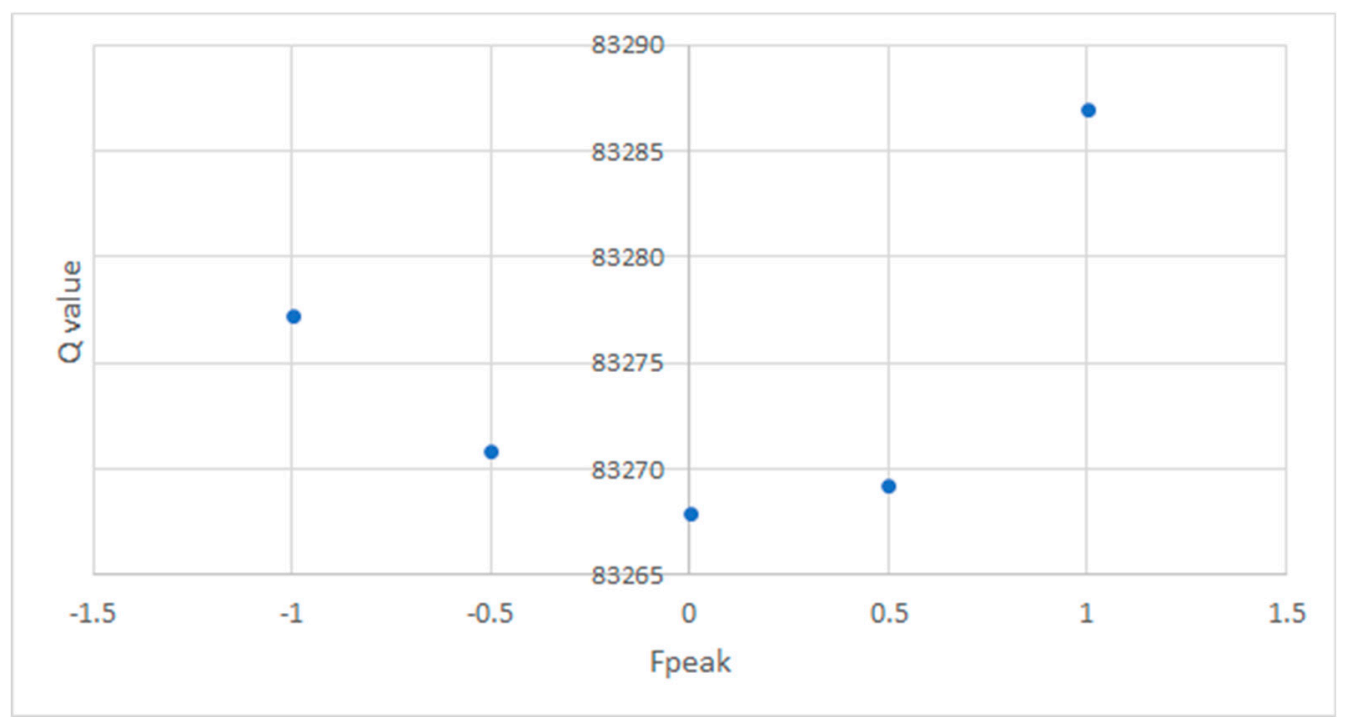

Figure A2. Q value determined for five factors for different Fpeak. 


\section{References}

1. Seinfeld, J.H.; Pandis, S.N. Atmospheric Chemistry and Physics: From Air Pollution to Climate Change; John Wiley \& Sons: Hoboken, NJ, USA, 2016; ISBN 9781118947401.

2. Monks, P.S.; Granier, C.; Fuzzi, S.; Stohl, A.; Williams, M.L.; Akimoto, H.; Amann, M.; Baklanov, A.; Baltensperger, U.; Bey, I.; et al. Atmospheric composition change-global and regional air quality. Atmos. Environ. 2009, 43, 5268-5350. [CrossRef]

3. Matsunaga, S.; Mochida, M.; Kawamura, K. Growth of organic aerosols by biogenic semi-volatile carbonyls in the forestal atmosphere. Atmos. Environ. 2003, 37, 2045-2050. [CrossRef]

4. Wang, T.; Xue, L.; Brimblecombe, P.; Lam, Y.F.; Li, L.; Zhang, L. Ozone pollution in China: A review of concentrations, meteorological influences, chemical precursors, and effects. Sci. Total Environ. 2017, 575, 1582-1596. [CrossRef] [PubMed]

5. Kesselmeier, J.; Staudt, M. An overview on Emission, Physiology and Ecology. J. Atmos. Chem. 1999, 33, 23-88. [CrossRef]

6. Kalogridis, A.-C.; Gros, V.; Bonsang, B.; Sarda-Esteve, R.; Genard, A.-C.; Boissard, C.; Fernandez, C.; Ormeño, E.; Bonnaire, N.; Baisnée, D.; et al. Étude des composés organiques volatils biogéniques émis par une forêt méditerranéenne. La Météorologie 2016, 93, 42-49. [CrossRef]

7. Kesselmeier, J.; Kuhn, U.; Wolf, A.; Andreae, M.O.; Ciccioli, P.; Brancaleoni, E.; Frattoni, M.; Guenther, A.; Greenberg, J.; De Castro Vasconcellos, P.; et al. Atmospheric volatile organic compound (VOC) at a remote tropical forest site in central Amazonia. Atmos. Environ. 2000, 34, 4063-4072. [CrossRef]

8. Wang, J.; Zhang, C.; Zhou, J. Determination and Characteristic Analysis of Atmospheric Non-Methane Hydrocarbons in a Regional Hub City of North China Plain Determination and Characteristic Analysis of Atmospheric Non-Methane Hydrocarbons in a Regional Hub City of North China Plain. IOP Conf. Ser. Earth Environ. Sci. 2019, 223, 012052. [CrossRef]

9. Jaars, K.; Beukes, J.P.; Van Zyl, P.G.; Venter, A.D.; Josipovic, M.; Pienaar, J.J.; Vakkari, V.; Aaltonen, H.; Laakso, H.; Kulmala, M.; et al. Ambient aromatic hydrocarbon measurements at Welgegund, South Africa. Atmos. Chem. Phys. 2014, 14, 7075-7089. [CrossRef]

10. Borbon, A.; Gilman, J.B.; Kuster, W.C.; Grand, N.; Chevaillier, S.; Colomb, A.; Dolgorouky, C.; Gros, V.; Lopez, M.; Sarda-Esteve, R.; et al. Emission ratios of anthropogenic volatile organic compounds in northern mid-latitude megacities: Observations versus emission inventories in Los Angeles and Paris. J. Geophys. Res. Atmos. 2013, 118, 2041-2057. [CrossRef]

11. Salameh, T.; Afif, C.; Sauvage, S.; Borbon, A.; Locoge, N. Speciation of non-methane hydrocarbons (NMHCs) from anthropogenic sources in Beirut, Lebanon. Environ. Sci. Pollut. Res. 2014, 21, 10867-10877. [CrossRef]

12. Keita, S.; Liousse, C.; Yoboué, V.; Dominutti, P.; Guinot, B.; Assamoi, E.-M.; Borbon, A.; Haslett, S.L.; Bouvier, L.; Colomb, A.; et al. Particle and VOC emission factor measurements for anthropogenic sources in West Africa. Atmos. Chem. Phys. 2018, 18, 7691-7708. [CrossRef]

13. Seco, R.; Peñuelas, J.; Filella, I. Short-chain oxygenated VOCs: Emission and uptake by plants and atmospheric sources, sinks, and concentrations. Atmos. Environ. 2007, 41, 2477-2499. [CrossRef]

14. IARC Working Group on the Evaluation of Carcinogenic Risks to Humans \& International Agency for Research on Cancer. IARC Monographs on the Evaluation of Carcinogenic Risks to Humans; World Health Organization: Lyon, France, 2006; Volume 88.

15. US Environmental Protection Agency. 2014 National Emissions Inventory, Version 2; Technical Support Document; US Environmental Protection Agency: Washington, DC, USA, 2018.

16. Cooke, M.C.; Utembe, S.R.; Carbajo, P.G.; Archibald, A.T.; Orr-Ewing, A.J.; Jenkin, M.E.; Derwent, R.G.; Lary, D.J.; Shallcross, D.E. Impacts of formaldehyde photolysis rates on tropospheric chemistry. Atmos. Sci. Lett. 2010, 11, 33-38. [CrossRef]

17. Friedfeld, S.; Fraser, M.; Ensor, K.; Tribble, S.; Rehle, D.; Leleux, D.; Tittel, F. Statistical analysis of primary and secondary atmospheric formaldehyde. Atmos. Environ. 2002, 36, 4767-4775. [CrossRef]

18. Rasmussen, R.; Went, F.W. Volatile organic material of plant origin in the atmosphere. Proc. Natl. Acad. Sci. USA 1965, 53, 215. [CrossRef]

19. Li, X.; Rohrer, F.; Brauers, T.; Hofzumahaus, A.; Lu, K.; Shao, M.; Zhang, Y.H.; Wahner, A. Modeling of $\mathrm{HCHO}$ and $\mathrm{CHOCHO}$ at a semi-rural site in southern China during the PRIDE-PRD2006 campaign. Atmos. Chem. Phys. 2014, 14, 12291-12305. [CrossRef] 
20. Wolfe, G.M.; Kaiser, J.; Hanisco, T.F.; Keutsch, F.N.; De Gouw, J.A.; Gilman, J.B.; Graus, M.; Hatch, C.D.; Holloway, J.; Horowitz, L.W.; et al. Formaldehyde production from isoprene oxidation across NOx regimes. Atmos. Chem. Phys. 2016, 16, 2597-2610. [CrossRef]

21. Baray, J.L.; Courcoux, Y.; Keckhut, P.; Portafaix, T.; Tulet, P.; Cammas, J.P.; Hauchecorne, A.; Godin Beekmann, S.; De Mazière, M.; Hermans, C.; et al. Maïdo observatory: A new high-altitude station facility at Reunion Island (21 S, 55 E) for long-term atmospheric remote sensing and in situ measurements. Atmos. Meas. Tech. 2013, 6, 2865-2877. [CrossRef]

22. Norris, G. EPA Positive Matrix Factorization (PMF) 3.0 Fundamentals \& User Guide; Environmental Protection Agency: Washington, DC, USA, 2008. Available online: http://www.epa.gov/heasd/products/pmf/pmf.html (accessed on 12 December 2018).

23. Yuan, B.; Shao, M.; De Gouw, J.; Parrish, D.D.; Lu, S.; Wang, M.; Zeng, L.; Zhang, Q.; Song, Y.; Zhang, J.; et al. Volatile organic compounds (VOCs) in urban air: How chemistry affects the interpretation of positive matrix factorization (PMF) analysis. J. Geophys. Res. Atmos. 2012, 117. [CrossRef]

24. Yuan, Z.; Kai, A.; Lau, H.; Shao, M.; Louie, P.K.K.; Liu, S.C.; Zhu, T.; Yuan, C.; Lau, A.K.H.; Shao, M.; et al. Source analysis of volatile organic compounds by positive matrix factorization in urban and rural environments in Beijing. J. Geophys. Res 2009, 114. [CrossRef]

25. Vlasenko, A.; Slowik, J.G.; Bottenheim, J.W.; Brickell, P.C.; Chang, R.Y.W.; Maedonald, A.M.; Shantz, N.C.; Sjostedt, S.J.; Wiebe, H.A.; Leaitch, W.R.; et al. Measurements of VOCs by proton transfer reaction mass spectrometry at a rural Ontario site: Sources and correlation to aerosol composition. J. Geophys. Res. Atmos. 2009, 114. [CrossRef]

26. Michoud, V.; Sciare, J.; Sauvage, S.; Dusanter, S.; Léonardis, T.; Gros, V.; Kalogridis, C.; Zannoni, N.; Féron, A.; Petit, J.-E.; et al. Organic carbon at a remote site of the western Mediterranean Basin: Sources and chemistry during the ChArMEx SOP2 field experiment. Atmos. Chem. Phys. 2017, 17, 8837-8865. [CrossRef]

27. Chan, Y.; Hawas, O.; Hawker, D.; Vowles, P.; Cohen, D.D.; Stelcer, E.; Simpson, R.; Golding, G.; Christensen, E. Using multiple type composition data and wind data in PMF analysis to apportion and locate sources of air pollutants. Atmos. Environ. 2011, 45, 439-449. [CrossRef]

28. Brémaud, P..; Taupin, F. Cloud influence on ozone diurnal cycle in the marine boundary layer at Réunion Island. Atmos. Res. 1998, 47-48, 285-298.

29. Duflot, V.; Tulet, P.; Flores, O.; Barthe, C.; Colomb, A.; Deguillaume, L.; Vaïtilingom, M.; Perring, A.; Huffman, A.; Hernandez, M.T.; et al. Preliminary results from the FARCE 2015 campaign: Multidisciplinary study of the forests-gases-aerosols-clouds system on the tropical island of La Réunion. Atmos. Chem. Phys. Discuss. 2019, 19, 10591-10618.

30. Lesouëf, D.; Gheusi, F.; Delmas, R.; Escobar, J.; Lesouëf, D.; Delmas, R. Numerical simulations of local circulations and pollution transport over Reunion Island. Eur. Geosci. Union 2011, 29, 53-69. [CrossRef]

31. Guilpart, E.; Vimeux, F.; Evan, S.; Brioude, J.; Metzger, J.-M.; Barthe, C.; Risi, C.; Cattani, O. The isotopic composition of near-surface water vapor at the Maïdo observatory (Reunion Island, southwestern Indian Ocean) documents the controls of the humidity of the subtropical troposphere. J. Geophys. Res. Atmos. 2017, 122, 9628-9650. [CrossRef]

32. Clain, G.; Baray, J.-L.; Delmas, R.; Keckhut, P.; Cammas, J.-P. A lagrangian approach to analyse the tropospheric ozone climatology in the tropics: Climatology of stratosphere-troposphere exchange at Reunion Island. Atmos. Environ. 2010, 44, 968-975. [CrossRef]

33. Wang, Y.; Shen, C.; Li, J.; Jiang, H.; Chu, Y. Proton Transfer Reaction Mass Spectrometry (PTR-MS). In Mass Spectrometry Handbook; John Wiley \& Sons, Inc.: Hoboken, NJ, USA; Volume 109, pp. 605-630. ISBN 9780470536735.

34. Blake, R.S.; Monks, P.S.; Ellis, A.M. Proton-Transfer Reaction Mass Spectrometry. Chem. Rev. 2009, 109, 861-896. [CrossRef]

35. Holzinger, R.; Acton, W.J.F.; Bloss, W.J.; Breitenlechner, M.; Crilley, L.R.; Dusanter, S.; Gonin, M.; Gros, V.; Keutsch, F.N.; Kiendler-Scharr, A.; et al. Validity and limitations of simple reaction kinetics to calculate concentrations of organic compounds from ion counts in PTR-MS. Atmos. Meas. Tech. Discuss. 2019, 12, 6193-6208. [CrossRef]

36. Tani, A.; Hayward, S.; Hewitt, C. Measurement of monoterpenes and related compounds by proton transfer reaction-mass spectrometry (PTR-MS). Int. J. Mass Spectrom. 2003, 223-224, 561-578. [CrossRef] 
37. Laffineur, Q.; Aubinet, M.; Schoon, N.; Amelynck, C.; Müller, J.-F.; Dewulf, J.; Van Langenhove, H.; Steppe, K.; Šimpraga, M.; Heinesch, B. Isoprene and monoterpene emissions from a mixed temperate forest. Atmos. Environ. 2011, 45, 3157-3168. [CrossRef]

38. Nash, T. The Colorimetric Estimation of Formaldehyde by Means of the Hantzsch Reaction. Biochem. J. 1953, 55, 416-421. [CrossRef] [PubMed]

39. Still, T.J.; Al-Haider, S.; Seakins, P.W.; Sommariva, R.; Stanton, J.C.; Mills, G.; Penkett, S.A. Ambient formaldehyde measurements made at a remote marine boundary layer site during the NAMBLEX campaign-a comparison of data from chromatographic and modified Hantzsch techniques. Atmos. Chem. Phys. 2006, 6, 2711-2726. [CrossRef]

40. Pollack, I.B.; Lerner, B.M.; Ryerson, T.B.; Pollack, I.B.; Lerner, B.M.; Ryerson, T.B. Evaluation of ultraviolet light-emitting diodes for detection of atmospheric $\mathrm{NO}_{2}$ by photolysis-chemiluminescence. J. Atmos Chem. 2010, 65, 111-125. [CrossRef]

41. Parrish, D.D.; Stohl, A.; Forster, C.; Atlas, E.L.; Blake, D.R.; Goldan, P.D.; Kuster, W.C.; De Gouw, J.A.; Parrish, C. Effects of mixing on evolution of hydrocarbon ratios in the troposphere. J. Geophys. Res 2007, 112, 10-34. [CrossRef]

42. Fried, A.; Mckeen, S.; Sewell, S.; Harder, J.; Henry, B.; Goldan, P.; Kuster, W.; Williams, E.; Baumann, K.; Shetter, R.; et al. Photochemistry of formaldehyde during the 1993 Tropospheric OH Photochemistry Experiment. J. Geophys. Res. 1997, 102, 6283-6296. [CrossRef]

43. White, M.L.; Russo, R.S.; Zhou, Y.; Ambrose, J.L.; Haase, K.; Frinak, E.K.; Varner, R.K.; Wingenter, O.W.; Mao, H.; Talbot, R.; et al. Atmospheric Chemistry and Physics Are biogenic emissions a significant source of summertime atmospheric toluene in the rural Northeastern United States? Atmos. Chem. Phys. 2009, 9, 81-92. [CrossRef]

44. Possanzini, M.; Di Palo, V.; Cecinato, A. Sources and photodecomposition of formaldehyde and acetaldehyde in Rome ambient air. Atmos. Environ. 2002, 36, 3195-3201. [CrossRef]

45. Zhang, Y.; Mu, Y.; Liang, P.; Xu, Z.; Liu, J.; Zhang, H.; Wang, X.; Gao, J.; Wang, S.; Chai, F.; et al. Atmospheric BTEX and carbonyls during summer seasons of 2008-2010 in Beijing. Atmos. Environ. 2012, 59, 186-191. [CrossRef]

46. Atkinson, R.; Arey, J. Gas-phase tropospheric chemistry of biogenic volatile organic compounds: A review. Atmos. Environ. 2003, 37, 197-219. [CrossRef]

47. Roberts, J.M.; Fehsenfeld, F.C.; Liu, S.C.; Bollinger, M.J.; Hahn, C.; Albritton, D.L.; Sievers, R.E. Measurements of aromatic hydrocarbon ratios and NOx concentrations in the rural troposphere: Observation of air mass photochemical aging and NOx removal. Atmos. Environ. 1984, 18, 2421-2432. [CrossRef]

48. Winters, A.J.; Adams, M.A.; Bleby, T.M.; Rennenberg, H.; Steigner, D.; Steinbrecher, R.; Kreuzwieser, J. Emissions of isoprene, monoterpene and short-chained carbonyl compounds from Eucalyptus spp. in southern Australia. Atmos. Environ. 2009, 43, 3035-3043. [CrossRef]

49. Kesselmeier, J.; Bode, K.; Hofmann, U.; Müller, H.; Schäfer, L.; Wolf, A.; Ciccioli, P.; Brancaleoni, E.; Cecinato, A.; Frattoni, M.; et al. Emission of short chained organic acids, aldehydes and monoterpenes from Quercus ilex L. and Pinus pinea L. in relation to physiological activities, carbon budget and emission algorithms. Atmos. Environ. 1997, 31, 119-133. [CrossRef]

50. Paatero, P.; Tapper, U. Positive matrix factorization: A non-negative factor model with optimal utilization of error estimates of data values. Environmetrics 1994, 5, 111-126. [CrossRef]

51. Sauvage, S.; Plaisance, H.; Locoge, N.; Wroblewski, A.; Coddeville, P.; Galloo, J.C. Long term measurement and source apportionment of non-methane hydrocarbons in three French rural areas. Atmos. Environ. 2009, 43, 2430-2441. [CrossRef]

52. Paatero, P.; Eberly, S.; Brown, S.G.; Norris, G.A. Methods for estimating uncertainty in factor analytic solutions. Atmos. Meas. Tech. 2014, 7, 781-797. [CrossRef]

53. Leighton, P. Photochemistry of Air Pollution; Elsevier Science: Amsterdam, The Netherlands, 1961; p. 158. ISBN 9780323156455.

54. Atkinson, R. Atmospheric chemistry of VOCs and NOx. Atmos. Environ. 2000, 34, 2063-2101. [CrossRef]

55. Bechara, J.; Borbon, A.; Jambert, C.; Colomb, A.; Perros, P.E. Evidence of the impact of deep convection on reactive Volatile Organic Compounds in the upper tropical troposphere during the AMMA experiment in West Africa. Atmos. Chem. Phys. 2010, 10, 10321-10334. [CrossRef] 
56. Keller, M.D.; Bellows, W.K.; Guillard, R.R.L. Dimethyl Sulfide Production in Marine Phytoplankton. ACS Publ. 1989, 167-182. [CrossRef]

57. Blake, N.J.; Blake, D.R.; Wingenter, O.W.; Sive, B.C.; Kang, C.H.; Thornton, D.C.; Bandy, A.R.; Atlas, E.; Flocke, F.; Harris, J.M.; et al. Aircraft measurements of the latitudinal, vertical, and seasonal variations of NMHCs, methyl nitrate, methyl halides, and DMS during the First Aerosol Characterization Experiment (ACE 1). J. Geophys. Res. Atmos. 1999, 104, 21803-21817. [CrossRef]

58. Holzinger, R.; Warneke, C.; Hansel, A.; Jordan, A.; Lindinger, W.; Scharffe, D.H.; Schade, G.; Crutzen, P.J. Biomass burning as a source of formaldehyde, acetaldehyde, methanol, acetone, acetonitrile, and hydrogen cyanide. Geophys. Res. Lett. 1999, 26, 1161-1164. [CrossRef]

59. de Gouw, J.A.; Warneke, C.; Parrish, D.D.; Holloway, J.S.; Trainer, M.; Fehsenfeld, F.C. Emission sources and ocean uptake of acetonitrile $(\mathrm{CH} 3 \mathrm{CN})$ in the atmosphere. J. Geophys. Res. D Atmos. 2003, 108, 1-8. [CrossRef]

60. Tuazon, E.C.; Atkinson, R. A product study of the gas-phase reaction of Isoprene with the OH radical in the presence of NOx. Int. J. Chem. Kinet. 1990, 22, 1221-1236. [CrossRef]

61. Monson, R.K.; Jaeger, C.H.; Adams, W.W.; Driggers, E.M.; Silver, G.M.; Fall, R. Relationships among isoprene emission rate, photosynthesis, and isoprene synthase activity as influenced by temperature. Plant Physiol. 1992, 98, 1175-1180. [CrossRef] [PubMed]

62. Atkinson, R.; Baulch, D.L.; Cox, R.A.; Crowley, J.N.; Hampson, R.F.; Hynes, R.G.; Jenkin, M.E.; Rossi, M.J.; Troe, J. Evaluated kinetic and photochemical data for atmospheric chemistry: Volume II-gas phase reactions of organic species. Atmos. Chem. Phys. 2006, 6, 3625-4055. [CrossRef]

63. Zhou, X.; Lee, Y.-N.; Newman, L.; Chen, X.; Mopper, K. Tropospheric formaldehyde concentration at the Mauna Loa Observatory during the Mauna Loa Observatory Photochemistry Experiment 2. J. Geophys. Res. Atmos. 1996, 101, 14711-14719. [CrossRef]

64. Neitzert, V.; Seiler, W. Measurements of formaldehyde in clean air. Geophys. Res. Lett. 1981, 8, 79-82. [CrossRef]

65. de Blas, M.; Ibáñez, P.; García, J.A.; Gómez, M.C.; Navazo, M.; Alonso, L.; Durana, N.; Iza, J.; Gangoiti, G.; de Cámara, E.S. Summertime high resolution variability of atmospheric formaldehyde and non-methane volatile organic compounds in a rural background area. Sci. Total Environ. 2019, 647, 862-877. [CrossRef]

66. Zheng, J.; Zhang, R.; Garzón, J.P.; Huertas, M.E.; Levy, M.; Ma, Y.; Torres-Jardón, R.; Ruiz-Suárez, L.G.; Russell, L.; Takahama, S.; et al. Measurements of formaldehyde at the U.S.-Mexico border during the Cal-Mex 2010 air quality study. Atmos. Environ. 2013, 70, 513-520. [CrossRef]

67. Oku, H.; Inafuku, M.; Takamine, T.; Nagamine, M.; Saitoh, S.; Fukuta, M. Temperature threshold of isoprene emission from tropical trees, Ficus virgata and Ficus septica. Chemosphere 2014, 95, 268-273. [CrossRef] [PubMed]

68. Kotzias, D.; Konidari, C.; Sparta, C. Volatile carbonyl compounds of biogenic origin. Emission and concentration in the atmosphere. In Biogenic Volatile Organic Carbon Compounds in the Atmosphere; SPB Academic Publishing: Amsterdam, The Netherlands, 1997; pp. 67-78.

69. Koppmann, R. Volatile Organic Compounds in the Atmosphere. In Volatile Organic Compounds in the Atmosphere; Blackwell Pub.: Oxford, UK, 2007; pp. 1-500. ISBN 9781405131155.

70. Millet, D.B.; Guenther, A.; Siegel, D.A.; Nelson, N.B.; Singh, H.B.; de Gouw, J.A.; Warneke, C.; Williams, J.; Eerdekens, G.; Sinha, V.; et al. Global atmospheric budget of acetaldehyde: 3-D model analysis and constraints from in-situ and satellite observations. Atmos. Chem. Phys. 2010, 10, 3405-3425. [CrossRef]

71. Yáñez-Serrano, A.M.; Nölscher, A.C.; Bourtsoukidis, E.; Derstroff, B.; Zannoni, N.; Gros, V.; Lanza, M.; Brito, J.; Noe, S.M.; House, E.; et al. Atmospheric mixing ratios of methyl ethyl ketone (2-butanone) in tropical, boreal, temperate and marine environments. Atmos. Chem. Phys. 2016, 16, 10965-10984. [CrossRef]

72. Perry, R.; Gee, I.L. Vehicle emissions in relation to fuel composition. Sci. Total Environ. 1995, 169, 149-156. [CrossRef]

73. Lacaux, J.P.; Loemba-Ndembi, J.; Lefeivre, B.; Cros, B.; Delmas, R. Biogenic emissions and biomass burning influences on the chemistry of the fogwater and stratiform precipitations in the African equatorial forest. Atmos. Environ. Part A. Gen. Top. 1992, 26, 541-551. [CrossRef]

74. Baudic, A.; Gros, V.; Sauvage, S.; Locoge, N.; Sanchez, O.; Sarda-Estève, R.; Kalogridis, C.; Petit, J.-E.; Bonnaire, N.; Baisnée, D.; et al. Seasonal variability and source apportionment of volatile organic compounds (VOCs) in the Paris megacity (France). Atmos. Chem. Phys. 2016, 16, 11961-11989. [CrossRef]

75. Peters, R. The determination of terpenes in forest air. Atmos. Environ. 1994, 28, 2413-2419. [CrossRef] 
76. Rose, C.; Chaumerliac, N.; Deguillaume, L.; Perroux, H.; Mouchel-Vallon, C.; Leriche, M.; Patryl, L.; Armand, P. Modeling the partitioning of organic chemical species in cloud phases with CLEPS (1.1). Atmos. Chem. Phys. 2018, 18, 2225-2242. [CrossRef]

77. Carter, W.P.L.; Atkinson, R. Development and evaluation of a detailed mechanism for the atmospheric reactions of isoprene and NOx. Int. J. Chem. Kinet. 1996, 28, 497-530. [CrossRef]

78. Stroud, C.A.; Roberts, J.M.; Goldan, P.D.; Kuster, W.C.; Murphy, P.C.; Williams, E.J.; Hereid, D.; Parrish, D.; Sueper, D.; Trainer, M.; et al. Isoprene and its oxidation products, methacrolein and methylvinyl ketone, at an urban forested site during the 1999: Southern Oxidants Study. J. Geophys. Res. Atmos. 2001, 106, 8035-8046. [CrossRef]

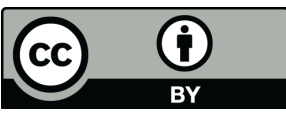

(C) 2020 by the authors. Licensee MDPI, Basel, Switzerland. This article is an open access article distributed under the terms and conditions of the Creative Commons Attribution (CC BY) license (http://creativecommons.org/licenses/by/4.0/). 